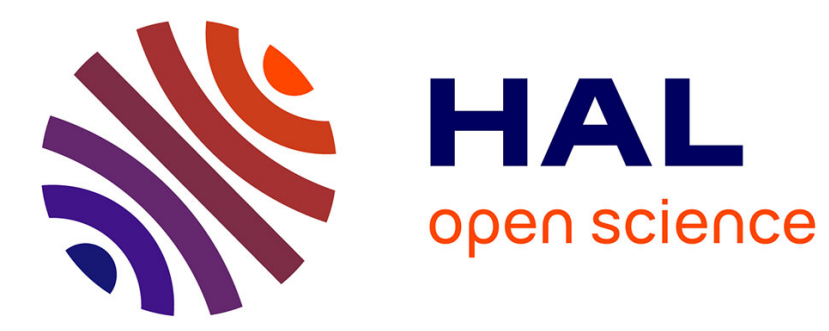

\title{
XPS monitoring of SrVO3 thin films from demixing to air ageing: The asset of treatment in water
}

Yoan Bourlier, Mathieu Frégnaux, Bruno Bérini, Arnaud Fouchet, Yves

Dumont, Damien Aureau

\section{- To cite this version:}

Yoan Bourlier, Mathieu Frégnaux, Bruno Bérini, Arnaud Fouchet, Yves Dumont, et al.. XPS monitoring of SrVO3 thin films from demixing to air ageing: The asset of treatment in water. Applied Surface Science, 2021, 553, pp.149536. 10.1016/j.apsusc.2021.149536 . hal-03238221

\section{HAL Id: hal-03238221 \\ https://hal.science/hal-03238221}

Submitted on 28 May 2021

HAL is a multi-disciplinary open access archive for the deposit and dissemination of scientific research documents, whether they are published or not. The documents may come from teaching and research institutions in France or abroad, or from public or private research centers.
L'archive ouverte pluridisciplinaire HAL, est destinée au dépôt et à la diffusion de documents scientifiques de niveau recherche, publiés ou non, émanant des établissements d'enseignement et de recherche français ou étrangers, des laboratoires publics ou privés. 
XPS monitoring of $\mathrm{SrVO}_{3}$ thin films from demixing to air ageing:

the asset of treatment in water

Yoan Bourlier* 1,2, Mathieu Frégnaux ${ }^{1}$, Bruno Bérini ${ }^{2}$, Arnaud Fouchet ${ }^{3}$, Yves Dumont ${ }^{2}$, Damien Aureau* 1

${ }^{1}$ ILV, CNRS UMR 8180, Université de Versailles Saint-Quentin-en-Yvelines - Université Paris-Saclay, Versailles, France

${ }^{2}$ GEMaC, Université Paris-Saclay, CNRS \& Université de Versailles Saint-Quentin-enYvelines, UMR 8635, Versailles, France

${ }^{3}$ NORMANDIE UNIV, ENSICAEN, UNICAEN, CNRS, CRISMAT, Caen, France

KEYWORDS: AR-XPS, $\mathrm{SrVO}_{3}$, surface spectroscopy, water, air ageing, PLD 


\section{ABSTRACT}

In this work, 40 nm-thick films of $\mathrm{SrVO}_{3}(\mathrm{SVO})$ grown by Pulsed Laser Deposition (PLD) on $\mathrm{SrTiO}_{3}$ substrates are studied by X-Ray Photoelectron Spectroscopy (XPS). We develop here a systematic fitting procedure for both $\mathrm{Sr} 3 \mathrm{~d}, \mathrm{~V} 2 \mathrm{p}_{3 / 2}$ and $\mathrm{O1s}$ spectral regions of interest associated to the different chemical environments. Joint angle resolved XPS and Ar ion depth profiling reveal that as-grown SVO thin films exhibits Sr-rich phases at the extreme surface and a near-stoichiometric SVO in the bulk. The removal of segregated $\mathrm{Sr}$ is proposed by a treatment in deionized ultrapure water. This step will become an essential technological step in order to obtain reproducible surfaces achieving a stoichiometric SVO oxide phase. Besides, these hydrolyzed SVO surfaces appears $\mathrm{VO}_{2}$ terminated and then more electrically active. Furthermore, an air-ageing comparative study between as-grown and $\mathrm{H}_{2} \mathrm{O}$-treated samples reveals that hydrolyzed surfaces are more surface sensitive to air oxidation. Such observations will be crucial and must be carefully considered before performing any passivation process for the integration of SVO thin film into next generation electronics heterostructures. 


\section{INTRODUCTION}

Metal oxide surfaces and interfaces analyses using X-ray photoelectron spectroscopy (XPS) have always been a matter of great interest $[1,2]$ with many applications of hightechnology materials in microelectronic devices, power generating cells and sensors $[3,4]$. Therefore, analyses of surfaces and especially photoemission techniques will be even more crucial in the coming development, where the film thicknesses become nanometric and are no longer governed by their bulk properties. Furthermore, perovskite oxides have focused lot of attention over last decades because of their various functionalities not available in classical semiconductor properties (such as superconductivity, ferrimagnetism, ferroelectricity, and metal-to-insulator transition) whether in bulk [5] or thin film materials [6], opening a new electronics field associated to the so-called "oxitronics", with several demonstrators [7]. The device's integration of metal oxide thin and ultrathin films as well as the existence of new properties generated at oxides interfaces such as $2 \mathrm{D}$ electron system at $\mathrm{LaAlO}_{3} / \mathrm{SrTiO}_{3}$ interface [8,9] require a fine surface/interface chemical spectroscopic analysis $[10,11]$ to access a full understanding.

In this context, this study focuses on $\mathrm{SrVO}_{3}(\mathrm{SVO})$ which is a strongly correlated transition metal oxide [12], presenting an excellent electronic conductivity [13], and a very low work function [14]. Since this perovskite oxide has a simple cubic structure with only one electron on the $d$ orbitals, it is a reference system to apply theoretical calculations related to photoemission studies in the domain of correlations [15-17]. Furthermore, due to its electronic correlations, this material has recently been considered as a new transparent conductive oxide which can have strong impact in microelectronic and particularly in the domain of optoelectronic [18]. SVO thin film optimization can also be pursued with respect to their metallic resistivity behaviour according to the resistivity ratio $(\mathrm{RRR}=\mathrm{Q}(300 \mathrm{~K}) / \mathrm{Q}(5 \mathrm{~K}))$ as a criterion of the density of low scattering centers at low temperature $[19,20]$. This material can 
also be particularly interesting for free standing membrane perovskite, since it has been used as a sacrificial layer, because of its entire solubilization in water for several hours [21].

As the electrical conductivity is related to the fine adjustment of the stoichiometry of the oxide, mastering the growth and optimization of these properties are quite challenging because of the strong influence of non-stoichiometry on electrical conductivity. The oxygen stoichiometry is usually not achieved due to instable oxidation degree of vanadium. Ideally, vanadium in SVO should be $\mathrm{V}^{4+}$. However, the growth is done under a low oxygen partial pressure or in presence of a reducing agent. Consequently, this process is difficult to handle and $\mathrm{V}^{3+}$ can also be formed in the films. Furthermore, in contact with air, vanadium tends to oxidize and a small layer with a higher oxidation state $\mathrm{V}^{5+}$ on top of vanadate material can be observed. Interestingly, in some specific growth conditions, nanostructures can even appear at the surface with a new phase $\left(\mathrm{Sr}_{3} \mathrm{~V}_{2} \mathrm{O}_{8}\right)$ which is epitaxially grown on the SVO matrix [22,23]. These Srrich nanostructures presenting a high oxidation state of vanadium $\left(\mathrm{V}^{5+}\right)$ evidence thermodynamic instabilities near the surface which will result in a stoichiometry modification of the material. The cationic stoichiometry is also an important factor since the transport properties are strongly related to this Sr/V ratio [24]. Particularly, SVO presents a robust metallic behaviour, even when the material presents some deviation of the oxygen stoichiometry or variations in the cationic ratios. Nevertheless, its stoichiometry should be optimized in order to obtain high conductivity and important mobility especially if considered as an electrode material.

Therefore, photoemission experiments were performed to probe the bulk and the surface of a freshly prepared SVO thin film grown by PLD, using XPS depth profiling and angle resolved XPS, respectively. In a second part, the use of a dissolution process with a treatment in deionized water in order to clean the surface from Sr-rich phases is investigated. The consequences on the different chemical environments detected will be explained. In the last 
part, air-ageing effects on SVO thin films are monitored to get a better understanding of the reactivity of these surfaces.

\section{MATERIAL AND METHODS}

\section{Synthesis of $\mathrm{SrVO}_{3}$ thin films}

The different $40 \mathrm{~nm}$-thick SVO films have been elaborated by pulsed laser deposition (PLD) using a $\mathrm{KrF}$ excimer laser with a wavelength of $248 \mathrm{~nm}$, a repetition rate of $2 \mathrm{~Hz}$ and an energy density on the target of $1.85{\mathrm{~J} . \mathrm{cm}^{2}}^{2}$. The base pressure of the chamber was $5 \times 10^{-9} \mathrm{mbar}$ and the distance between the target and the substrate was fixed at $5 \mathrm{~cm}$. The deposition temperature was kept constant at $770^{\circ} \mathrm{C}$ in an oxygen pressure of $1.2 \times 10^{-6}$ mbar. After deposition, the films were cooled down to room temperature under vacuum in order to obtain smooth films. The films were deposited onto single-crystal $\mathrm{SrTiO}_{3}(100)$ substrates (SurfaceNet $\mathrm{GmbH}$ ). The SVO target was synthesized in the GEMaC using a stoichiometric mixture of $\mathrm{SrO}$ and $\mathrm{VO}_{2}$ oxide powders. Its stoichiometry was controlled by SEM (Scanning Electron Microscopy) - EDX (Energy-Dispersive X-ray spectroscopy) and a cationic ratio of $1.00 \pm 0.03$ was estimated.

\section{XPS characterization}

As-grown SVO samples are transferred from the PLD chamber to a glove box in order to be mounted on an adapted sample holder for X-ray Photoelectron Spectroscopy (XPS) analyses. Using this procedure, the samples have been exposed to air less than 2 minutes.

Regular and Angle-Resolved XPS (ARXPS) analyses were conducted on a Thermofisher Scientific Escalab 250 xi equipped with a monochromated Al-Ka anode $(1486.6 \mathrm{eV})$ and a dual flood gun (low energy electron and ion). High energy resolution spectral windows of interest were recorded with a $650 \mu \mathrm{m}$ spot size. The photoelectron detection was 
performed using a constant analyzer energy (CAE) mode (10 eV pass energy) and a $0.1 \mathrm{eV}$ energy step. All the associated binding energies were corrected with respect to the Fermi level energy within the valence band spectral region assuming that SVO is a conductive oxide. The ARXPS spectra were collected by tilting the sample holder with a photoelectron take-off angle, $\theta$, with respect to the normal of the surface, ranging from $0^{\circ}$ to $70^{\circ}$ with a $10^{\circ}$ step.

XPS depth profiling required the use of the Thermofisher Scientific MAGCIS dualbeam ion gun. Monoatomic Argon $\left(\mathrm{Ar}^{+}\right)$ions were accelerated to reach the sample with a kinetic energy of $4000 \mathrm{eV}$ and an angle of $30^{\circ}$ from the surface normal. The SVO thin films were irradiated on a square area of $2 \times 2 \mathrm{~mm}^{2}$. In these sputtering conditions, an average etching rate of $0.03 \mathrm{~nm} \cdot \mathrm{s}^{-1}$ is observed on our SVO samples.

Quantification was performed based on the $\mathrm{O} 1 \mathrm{~s}, \mathrm{C} 1 \mathrm{~s}, \mathrm{Sr} 3 \mathrm{~d}_{5 / 2}$ and $\mathrm{V} 2 \mathrm{p}_{3 / 2}$ photopeak areas after a Shirley type background subtraction using the Thermofisher Scientific Avantage $\mathbb{C}$ software and its "ALTHERMO1" library as sensitivity factor collection. A Voigt function with $\mathrm{L} / \mathrm{G}=20 \%$ was used during our SVO generic fitting procedure developed for this work.

\section{Other characterizations}

Some experiments have been performed afterwards, onto a dedicated sample elaborated in the same conditions. Film thicknesses have been determined by conventional stepmeter measurements (Bruker Dektak 8). The topography and the roughness of the films have been investigated by AFM (Bruker ICON) in PeakForce Tapping mode using commercial tips (Bruker, ScanAsyst-Air).

$X$-ray diffraction (XRD) analysis on thin films was carried out using a $\theta-2 \theta$ instrument (Bruker D8 Discover diffractometer, $\mathrm{Cu} \mathrm{K}_{\alpha 1}$ radiation, $\lambda=1.5406 \AA$ ).) 


\section{RESULTS AND DISCUSSION}

This work relies on $40 \mathrm{~nm}$-thick $\mathrm{SrVO}_{3}$ (SVO) thin-films grown on a $\mathrm{SrTiO}_{3}(001)$ substrate by Pulsed Laser Deposition (PLD) technique. All analyzed samples exhibit a smooth surface with a RMS (Root Mean Square average roughness) inferior to $1 \mathrm{~nm}$, measured by AFM (Atomic Force Microscope) (see figure S1 in supporting information). These SVO samples were transferred with special care (limited air exposure) from the PLD chamber to the XPS load-lock. XPS quantitative analyses indicate that these transfer conditions allow us to minimize the amount of adventitious carbon on SVO surface, from 6 at.\% to 25 at.\%. A global $\mathrm{Sr} / \mathrm{V}$ atomic ratio between 1.4 and 1.6 at the sample surface is also revealed.

\section{XPS study of as-grown $\mathrm{SrVO}_{3}$ thin-film by pulsed laser deposition}

The "as-grown SVO" thin-film presented below will be taken as a reference material for the rest of the paper. The significant $\mathrm{Sr}$ enrichment detected on top surface motivated an indepth analysis. Using a monoatomic argon ion $\left(\mathrm{Ar}^{+}\right)$source gun inside the XPS analysis chamber, the SVO thin film has been entirely etched in order to evaluate the chemical composition of the whole layer. Figure 1 presents a typical in-depth profile showing the overall atomic percentage evolutions, deduced from the spectral windows of interest $\mathrm{Sr} 3 \mathrm{~d}, \mathrm{~V} 2 \mathrm{p}_{3 / 2}, \mathrm{C} 1 \mathrm{~s}$, $\mathrm{O} 1 \mathrm{~s}$, and Ti2p as a function of the sputtered thickness.

The XPS acquisition of the pristine SVO surface, before sputtering, exhibits for this sample a Sr-rich surface with a global $\mathrm{Sr} / \mathrm{V}$ ratio of around $1.55 \pm 0.10$. The carbon content rapidly decreases from an initial amount of $18.0 \pm 0.5$ at. $\%$ to 0.0 at. $\%$ after the very first etching steps. Such behavior is consistent with small organic molecules only related to physisorbed species. No carbon is detected by XPS inside the grown oxide layer. Between 100 and $700 \mathrm{sec}$, an averaged amount of $19.4 \pm 0.5$ at.\% of strontium and $18.7 \pm 0.5$ at.\% of vanadium are 
observed. Starting from $800 \mathrm{sec}$, the increase of the titanium amount is associated with the decrease of vanadium, which is related to the crossing of the SVO/STO interface.

The bulk region of SVO, between 100 and $700 \mathrm{sec}$, allow us to estimate an averaged $\mathrm{Sr} / \mathrm{V}$ ratio of $1.04 \pm 0.05$ which is consistent with a crystallized phase of perovskite $\mathrm{SrVO}_{3}$ revealed by XRD analysis (see figure $\mathbf{S 2}$ from supporting information). Thus, the in-depth XPS composition of the as-grown SVO thin-film tends to evidence a stoichiometric $\mathrm{SrVO}_{3}$ oxide through the bulk and confirms that the Sr-enrichment is only detected at the extreme surface of the film within no more than three nanometers. It seems that such $\mathrm{Sr}$ surface enrichment is more likely inherent to the necessary cooling time inside the chamber at the end of the PLD growth process [22] than air-ageing (very short time air exposure here).

The XPS depth profiling provides a good estimation of the $\mathrm{Sr} / \mathrm{V}$ ratio through the bulk SVO thin film, but the information about the different chemical environments involved is no longer accessible. Indeed, sputtering sources are known to induce disorder (atomic implantation inside the matrix, amorphization, elemental dissociation, and/or chemical reduction) [25,26]. In this work, a clear modification of the Sr3d, and O1s-V2p spectral regions induced by $\mathrm{Ar}^{+}$ion bombardment is observed, making the data not suitable to determine with accuracy the nature of chemical bindings during the depth profiling (see figure $\mathbf{S 3}$ in supporting information).

Consequently, in order to investigate the chemical environments on the as-grown SVO reference, we focused our study on the high-resolution XPS spectra recorded on a pristine surface without any treatment or sputtering. Figures $\mathbf{2 a}$. and 2b., present the O1s-V2p and Sr3d regions of interest, respectively, and the reconstructed spectra obtained using our systematic fitting procedure. As mentioned within the literature [27,28], we use a single Shirley to perform a global fit of the entire $\mathrm{O} 1 \mathrm{~s}-\mathrm{V} 2 \mathrm{p}$ region. At this point, we would like to mention that the choice of the most adapted Shirley background for wide spectral regions remains a hot topic in the community. The strategy, applied for instance for Ni2p [29,30] or Au4f [31], of successive 
Shirley backgrounds to separately fit $\mathrm{O} 1 \mathrm{~s}$ (from $536 \mathrm{eV}$ to $527 \mathrm{eV}$ ) and $\mathrm{V} 2 \mathrm{p}_{3 / 2}$ regions (from $521 \mathrm{eV}$ to $512 \mathrm{eV}$ ) appears well-adapted here to better adjust the experimental line but tend to underestimate the XPS vanadium content.

General fitted parameters: Binding Energy (BE) and Full Width at Half Maximum (FWHM), with their associated peak attributions are gathered in table 1. All the associated binding energies are corrected with respect to the Fermi level energy within the valence band spectral region knowing that SVO is a conductive oxide.

Figure 2a. highlights the fitting procedure for the O1s-V2p region of the as-grown SVO. Even if oxygen is a matter of great interest for perovskite oxides, the attribution of the different O1s components in XPS spectra is rarely reported in the literature. In this study, we propose a possible way to discriminate and quantify the different sources of detected oxygen atoms. Thus; four contributions can be extracted from the O1s spectral window. As a consequence of the energy correction described above, the first one, is settled at a BE of $529.2 \pm 0.05 \mathrm{eV}$ for all samples. This component appears sharp, with a FWHM of $0.85 \mathrm{eV}$. The second one is positioned around $530.0 \mathrm{eV}$, with a similar FWHM. These two first components, at lower BEs can be related to the SVO matrix, more specifically to a SVO perovskite lattice "O1s (lattice SVO)", and to a more surface sensitive SVO phase "O1s (surface SVO)" which could be associated to a more oxygen-rich surface layer. This differentiation between the so-called lattice and the surface perovskite oxide has been described in other works dealing with strontium-based perovskite oxides such as $\mathrm{SrRuO}_{3}$ [32], $\mathrm{Sr}_{2} \mathrm{Co}_{2} \mathrm{O}_{5}$ [33], and ( $\left.\mathrm{La}, \mathrm{Sr}\right)(\mathrm{Co}, \mathrm{Fe}) \mathrm{O}_{3}$ family compounds [34-38]. This behavior in SVO is explained by the multiple valence states of vanadium which would lead to a distribution within the O1s spectra [39]. The third contribution in $\mathrm{O} 1 \mathrm{~s}$ region is detected at around $530.6 \mathrm{eV}$ with a slightly greater FWHM of $1.05 \mathrm{eV}$. This position can be related to oxygen atoms linked to single metal or metal hydroxide present at the extreme surface, therefore named "O1s (O-M)". Such component is associated here to Sr-O 
and/or Sr-OH phases, resulting from the Sr-rich surface of the as-grown SVO thin film $[34,40,41]$. The last contribution of the O1s spectra, around $531.7 \mathrm{eV}$, named "O1s (O-C, OH)", appears broader, with a FWHM of $1.85 \mathrm{eV}$. This component is related to oxygen coming from organic surface contamination and physisorbed species.

Concerning the $\mathrm{V} 2 \mathrm{p}_{3 / 2}$ region, three different components can be separated from $512 \mathrm{eV}$ to $520 \mathrm{eV}$. V2 $\mathrm{p}_{3 / 2}$ signal can be reconstructed as followed: a first component at the highest $\mathrm{BE}$ of $517.7 \mathrm{eV}$; a second one at a $\mathrm{BE}$ around $516.7 \mathrm{eV}$; and finally, a third one at a $\mathrm{BE}$ around $515.0 \mathrm{eV}$. The FWHM is progressively increasing from 1.7 to $1.9 \mathrm{eV}$. As a first approximation, in a perfect SVO crystal, we should expect the oxidation degree of vanadium atoms to be $\mathrm{V}^{4+}$ to achieve electronic neutrality. However, the multiple valence of $\mathrm{V}$ is a well-known referenced behavior. This transition metal in its $\mathrm{V}^{4+}$ oxidation state appears unstable and tends to a partial dismutation into $\mathrm{V}^{5+}$ and $\mathrm{V}^{3+}[23,42]$. The vanadium electronic states mobility was already described by C. Lin et al. as a possible explanation of the SVO conducting behavior [39]. Consequently, the three components described above are attributed to "V2 $\mathrm{p}_{3 / 2}(5+)$ ", "V2 $\mathrm{p}_{3 / 2}$ $(4+)$ ", and "V2 $\mathrm{p}_{3 / 2}(3+)$ " referring to their respective vanadium oxidation states $\mathrm{V}^{5+}, \mathrm{V}^{4+}$ and $\mathrm{V}^{3+}$ (starting from the highest to the lowest BE). The BEs have been set with fixed negative shifts from $\mathrm{V}^{5+}$ (table 1) and are consistent with other XPS related works in vanadium oxides $[28,43,44]$. The slight gradient of FWHM from $\mathrm{V}^{5+}$ to $\mathrm{V}^{4+}$ and $\mathrm{V}^{3+}$ is in agreement with literature values and could be explained by the fact that $\mathrm{V}^{5+}$ species do not have unpaired valence electrons compared to $\mathrm{V}^{4+}$ and $\mathrm{V}^{3+}$ species [27]. As $\mathrm{V}^{3+}$ component is slightly broader, an eventual V2p $3 / 2(2+)$ component, not considered here, cannot be totally excluded. However, such reduce state have not been reported yet within the literature of $\mathrm{SrVO}_{3}$. The $\mathrm{V}_{2} \mathrm{p}_{1 / 2}$ region has been reconstructed following the constraints of the spin-orbit splitting $(\Delta \mathrm{E}=7.5 \pm 0.2 \mathrm{eV})$ with an area ratio of 1:2) and the broadening of FWHMs (from 3.2 to $3.4 \mathrm{eV}$ ) due to CostnerKronig effect. 
Figure 2b. presents the XPS spectrum of the Sr3d region and its reconstruction using our systematic fitting procedure. In this case, two different doublets and therefore chemical environments can clearly be extracted. Indeed, a first sharp $\mathrm{Sr}_{3} \mathrm{~d}_{5 / 2}$ peak, at a BE of $132.7 \mathrm{eV}$, with a FWHM of $0.75 \mathrm{eV}$, can be distinguished from a broader one, at a fixed BE positive shift of $1.05 \mathrm{eV}$, with a FWHM of $1.30 \mathrm{eV}$. Associated $\mathrm{Sr}_{3} \mathrm{~d}_{3 / 2}$ peaks have been fitted with a fixed spin orbit splitting of $1.75 \pm 0.02 \mathrm{eV}[41,45]$, an equal FWHM, and an area ratio of 0.67 to their respective $\operatorname{Sr} 3 \mathrm{~d}_{5 / 2}$ peaks. The sharp signature is consistent with a well-ordered crystalized structure, attributed to $\mathrm{Sr}$ atoms implied in the SVO perovskite matrix and has been named "Sr3d $\mathrm{d}_{5 / 2}(\mathrm{SVO}) "$. These values are consistent with the ones reported in the literature for SVO [46], and other conductive oxides, $\mathrm{SrRuO}_{3}$ [32] and $(\mathrm{La}, \mathrm{Sr})(\mathrm{Co}, \mathrm{Fe}) \mathrm{O}_{3}$ family compounds $[35,36,38]$. The wider $\operatorname{Sr} 3 \mathrm{~d}_{5 / 2}$ contribution can be attributed to isolated strontium oxide or hydroxide phases (mixing of poorly crystalized and/or amorphous phases) and named " $\mathrm{Sr} 3 \mathrm{~d}_{5 / 2}$ (Sr-O)"

The detailed fitting procedure described previously is then applied to AR-XPS data recorded on as-grown SVO in order to identify the chemical environments along the "Z" axis, from buried species to the most surface sensitive ones. Figures 3a., 3b., and 3c. represent the resulting high energy resolution spectra of $\mathrm{Sr} 3 \mathrm{~d}, \mathrm{~V} 2 \mathrm{p}_{3 / 2}$, and $\mathrm{O} 1 \mathrm{~s}$ regions, respectively. XPS spectra are recorded from a normal incidence " $\theta=0^{\circ}$ " until a grazing angle " $\theta=70^{\circ}$ ", where " $\theta$ " is the angle between the normal of the sample and the photoelectron detector. AR-XPS spectra have been normalized with respect to the peak area after background subtraction. A strong angle dependency is observed for the spectral regions of interest. Regarding the $\operatorname{Sr} 3 \mathrm{~d}_{5 / 2}$ (SVO) component at $132.7 \mathrm{eV}$, a high decrease of peak intensity with $\theta$ is clearly observed. This phenomenon is concomitant with another decreased intensity at higher angles of the O1s (lattice SVO) component at $529.2 \mathrm{eV}$. The large spectral signature of $\mathrm{V} 2 \mathrm{p}_{3 / 2}$ region, is also affected with a decreasing intensity between $514 \mathrm{eV}$ and $516.5 \mathrm{eV}$ with $\theta$ which are associated 
to $\mathrm{V}^{3+}$ and $\mathrm{V}^{4+}$. A decreasing intensity for these components justifies that there are related to the most buried chemical species. Conversely, an increase of "Sr3d (Sr-O)", "V2 $\mathrm{p}_{3 / 2}(5+)$ ", and the other O1s components is observed with increasing $\theta$ which confirms their location close to the surface.

Furthermore, a slightly grading shift of the "Sr3d $\mathrm{d}_{5 / 2}$ (SVO)" peak positions can be observed with a $\triangle \mathrm{BE}=+0.1 \mathrm{eV}$ between $0^{\circ}$ and $70^{\circ}$, which could be assessed to a slight band bending of the as-grown SVO surface This is consistent with a Sr terminated surface that would have a more insulating behaviour $[47,48]$.

Global "Sr/V" and "( $\mathrm{Sr}+\mathrm{V})) / \mathrm{O}_{\mathrm{ox}}$ " atomic percentage ratios with respect to the tilt angle $\theta$ are presented in figure 4. "O $\mathrm{O}_{\mathrm{ox}}$ " is the oxygen content related to $\mathrm{SrO}$ and $\mathrm{SVO}$, exempt from physisorbed species (see the "O1s (O-C, O-H)" component introduced in figure 2a.). "Sr/V" global ratio is relatively constant with an averaged value of $1.28 \pm 0.05$ from $0^{\circ}$ to $40^{\circ}$, and increases at higher angles until $1.55 \pm 0.05$ for $\theta=70^{\circ}$. "( $\left.\left.\mathrm{Sr}+\mathrm{V}\right)\right) / \mathrm{O}_{\mathrm{ox}}$ " ratio is also increasing from $0.80 \pm 0.02$ at $0^{\circ}$ to $0.95 \pm 0.02$ at $70^{\circ}$. Such high values highlight the fact that as-grown SVO is strongly governed by $\mathrm{Sr}$-rich phases which can be assimilated to $\mathrm{SrO}$ in excess. This phenomenon is commonly explained by a $\mathrm{Sr}$ segregation in the first nanometers $[47,49]$, and seems to be inherent to all physical growth process.

In the light of our systematic SVO fitting procedure described for as-grown SVO at normal incidence (figures 2 and table 1) and the associated AR-XPS analysis (figures 3), the quantitative evolution of all the components from $0^{\circ}$ to $70^{\circ}$ are looked in details. Figures 5a., 5b., and 5c. represent the relative proportions of the different chemical environments with respect to the global amount of $\mathrm{Sr} 3 \mathrm{~d}, \mathrm{~V} 2 \mathrm{p}_{3 / 2}$, and $\mathrm{O} 1 \mathrm{~s}$. The "Sr3d $\mathrm{d}_{5 / 2}(\mathrm{Sr}-\mathrm{O})$ " contribution (figure 5a.) represents $42 \%$ of the signal at $0^{\circ}$ and increases to $60 \%$ at $70^{\circ}$, proving that the upper surface is mainly made of $\mathrm{SrO}$ species. Conversely, the "Sr3d $\mathrm{d}_{5 / 2}(\mathrm{SVO})$ " signal decreases at 
grazing angles which confirms that the SVO perovskite is covered by this Sr-rich layer. Concerning the evolution of the $\mathrm{V} 2 \mathrm{p}_{3 / 2}$ contributions (figure 5b.), the three components are in equal proportion $(33 \%)$ at $0^{\circ}$. "V2 $\mathrm{p}_{3 / 2}(5+)$ " exhibits an increase up to $60 \%$ at $70^{\circ}$, conversely to the decrease of "V2 $\mathrm{p}_{3 / 2}(4+)$ " and "V2 $\mathrm{p}_{3 / 2}(3+)$ " down to $20 \%$ at $70^{\circ}$. It indicates that the Srrich surface is also accompanied by a proportion of $\mathrm{V}^{5+}$, probably related to $\mathrm{V}_{2} \mathrm{O}_{5}$ surface oxide or $\mathrm{Sr}_{3} \mathrm{~V}_{2} \mathrm{O}_{8-\delta}$ nuclei [49], two phases which are impossible to distinguish at this step. Finally, we observe in figure 5c. the evolution of the O1s contributions with the tilt angle. "O1s (lattice SVO)" is found to decrease from $40 \%$ at $0^{\circ}$ to $25 \%$ at $70^{\circ}$, while all other components are slightly increasing (from $0^{\circ}$ to $70^{\circ}$ ): "O1s (surface SVO)" from $12 \%$ to $16 \%$, "O1s (O-M)" from $18 \%$ to $21 \%$, and "O1s (O-C, O-H)" from $30 \%$ to $38 \%$.

In summary, these analyses indicate that the as-grown SVO exhibits from the extreme surface to the buried phases: (1) physisorbed species including organic contamination, (2) a phase with $\mathrm{Sr} / \mathrm{V}$ ratio around 1.5 and an overoxidized vanadium which can be attributed to single oxide phases poorly crystallized mainly $\mathrm{SrO}$ with a small amount of $\mathrm{V}_{2} \mathrm{O}_{5}$ and (3) the SVO perovskite oxide stoichiometric phase (with a $\mathrm{Sr} / \mathrm{V}=1$ as highlighted during the depth profiling in figure 1). All the quantitative data for the resulting XPS chemical composition are finally gathered in table 2 . These values could be explained by a surface demixing or phase segregation characterized by $6.5 \pm 0.1$ at.\% of $\mathrm{SrO}$ and by $2.7 \pm 0.3$ at.\% of $\mathrm{V}_{2} \mathrm{O}_{5}$ oxide estimated from AR-XPS results.

This model provides a good overview of the as-grown SVO system in the first nanometers. The surface exhibits a Sr-rich surface region on top, mainly $\mathrm{SrO}$ with a little fraction of $\mathrm{V}_{2} \mathrm{O}_{5}$ due to surface demixing, and a stoichiometric crystallized SVO underlayer. Indeed, with a Sr content of $9.0 \pm 0.1$ at.\%, an overall V content of $9.3 \pm 0.3$ at.\%, and a global amount of oxygen coming from lattice and surface SVO of $25.9 \pm 0.2$ at.\%, the buried SVO phase appears very close to the expected stoichiometry. 


\section{2. $\mathrm{SrVO}_{3}$ surface study after preferential etching with treatment in water}

Several Sr-based perovskites are likely to exhibit oxide compounds with Sr-rich surfaces. The possibility to selectively etch $\mathrm{SrO}$ from the surface has been referenced for $\mathrm{SrTiO}_{3}$ in order to obtain clean $\mathrm{TiO}_{2}$ terminated surface [50-52]. In a previous work, we demonstrated that Sr-rich phases segregated on top of SVO could be readily removed using only a treatment in deionized water for three minutes. A global " $\mathrm{Sr} / \mathrm{V}$ " ratio of 1.0 is then measured by XPS [49], leading to a surface close to the bulk which is interesting for electrode applications.

Consequently, this part is dedicated to a 3 min-long treatment in deionized ultrapure water (18.2 M $\Omega . c m)$ on as-grown SVO smooth thin film in order to study the evolution of the different chemical environments that are involved on the SVO surface. Figures 6a. and $\mathbf{6 b}$., present the XPS spectra of the regions of interest O1s-V2p and Sr3d and their reconstruction using our systematic fitting procedure for as-grown SVO sample treated in water. In figure 6a., four contributions can be extracted from the O1s spectral window, similarly to the one presented in figure 2a. with identical fitting constraints.

On an other hand, the general $\mathrm{V} 2 \mathrm{p}_{3 / 2}$ signature after rinsing is different from the asgrown one presented in figure $2 \mathbf{a} .$. By importing the $\mathrm{V} 2 \mathrm{p}_{3 / 2}$ fitting parameters obtained for the as-grown SVO, taken as a reference, the envelope of the rinsed sample is not fully reconstructed. A new component which can be naturally associated to hydroxide vanadium species must be added to perform a correct fitting. This additional chemical environment named "V2 $\mathrm{p}_{3 / 2}(\mathrm{~V}-\mathrm{OH})$ " is centred at the same binding energy as the "V2 $\mathrm{p}_{3 / 2}(4+)$ " component and appears slightly broader, with a FWHM of $2.0 \mathrm{eV}$. Such hydroxide species can be explained by the hydrolysis of SVO following the full chemical reaction: " $\mathrm{SrVO}_{3}+3 \mathrm{H}_{2} \mathrm{O} \rightarrow \mathrm{Sr}(\mathrm{OH})_{2}+$ $\mathrm{V}(\mathrm{OH})_{4}$ ". Then, hydrated species can be easily assessed to $\mathrm{V}^{4+}$ species in majority. 
The Sr3d spectral region of the $\mathrm{H}_{2} \mathrm{O}$-treated SVO, presented in figure 6c., shows a similar shape compared to the one before rinsing (figure 2c.). Nevertheless, a substantial decrease of the wide surface component "Sr3d $(\mathrm{Sr}-\mathrm{O})$ " can be observed after treatment in water. As $\mathrm{Sr}-\mathrm{O}$ and $\mathrm{Sr}-\mathrm{OH}$ chemical bounds have similar BE, the fitting parameters appears too close to be separated and are considered identical. Moreover, additional three minutes-time treatment in water (or even longer-time) do not further reduce the "Sr3d (Sr-O)" relative proportion. As $\mathrm{SrO}$ species are easily solubilized in water, we can assume that most of $\mathrm{SrO}$ surface oxide has been removed after such treatment. So, we deduced that "Sr3d (Sr-O)" component will be mainly associated to $\mathrm{Sr}-\mathrm{OH}$ bounds at this step, by analogy to other chemical treatments performed on well-referenced surface such as surface hydroxylation of $\mathrm{SrTiO}_{3}[52-54]$ and $\mathrm{Si}$ wafer [55-58].

Figures 7a., 7b., and 7c., represent the high energy resolution spectra of O1s, V2 $\mathrm{p}_{3 / 2}$, and $\mathrm{Sr} 3 \mathrm{~d}$ in angle resolved mode for the $\mathrm{H}_{2} \mathrm{O}$-treated $\mathrm{SVO}$, respectively. As for as-grown $\mathrm{SVO}$ (figures 3), we first observed the decrease of the "Sr3 $\mathrm{d}_{5 / 2}$ (SVO)" peak intensity, which occurs simultaneously with the decrease of "O1s lattice (SVO)" peak from " $\theta=0^{\circ}$ " until " $\theta=70^{\circ}$ ". The other components of $\mathrm{O} 1 \mathrm{~s}$, defined in figure 2a., and also the " $\mathrm{Sr} 3 \mathrm{~d}(\mathrm{Sr}-\mathrm{O})$ " component, associated to $\mathrm{Sr}-\mathrm{OH}$, increase with $\theta$ which shows their location at the upper surface. However, $\mathrm{V} 2 \mathrm{p}_{3 / 2}$ general shape appears quite unchanged with $\theta$ (figure 7b.). Only a slight increase of the global intensity is discernible at the most grazing angle $\left(\theta=70^{\circ}\right)$. This could be explained by an overall decrease of the three vanadium components assigned to $\mathrm{SVO}\left(\mathrm{V}^{5+}, \mathrm{V}^{4+}\right.$, and $\left.\mathrm{V}^{3+}\right)$, coupled to an increase of the vanadium hydroxide species ("V2 $\mathrm{p}_{3 / 2}(\mathrm{~V}-\mathrm{OH})$ ") which will result to an identical shape of the $\mathrm{V} 2 \mathrm{p}_{3 / 2}$ region at the different angles.

Another interesting point can be observed from AR-XPS analysis and has to be stressed out. A grading negative shift of the " $\mathrm{Sr}_{3} \mathrm{~d}_{5 / 2}$ (SVO)" peak positions can be observed (figure 7a.) with a $\triangle \mathrm{BE}=-0.2 \mathrm{eV}$ between $0^{\circ}$ and $70^{\circ}$. This observation may be attributed to a band bending 
which is consistent with a better surface conductivity at grazing angles. It could be linked to the more metallic behaviour of the SVO surface due to $\mathrm{VO}_{2}$-terminations in the case of rinsed sample compared to a more insulating SrO-terminations for as-grown samples (figure 3a.) as reported in in a recent SVO surface study [59].

Global "Sr/V" and " $(\mathrm{Sr}+\mathrm{V})) / \mathrm{O}_{\mathrm{ox}}$ " ratios related to the tilt angle $\theta$ for an $\mathrm{H}_{2} \mathrm{O}$-treated SVO thin film are presented in figure 8. "Sr/V" global ratio is decreasing from $0.95 \pm 0.03$ at $0^{\circ}$ to $0.70 \pm 0.03$ at $70^{\circ}$. " $\left.(\mathrm{Sr}+\mathrm{V})\right) / \mathrm{O}_{\text {ox }}$ " ratio is found constant from $0^{\circ}$ to $40^{\circ}$ with an averaged ratio of $0.67 \pm 0.02$, with a slight increasing for higher angles until $0.75 \pm 0.02$ at $70^{\circ}$. The global ratios are then perfectly consistent with a dominating stoichiometric SVO at $0^{\circ}$. For grazing angles, the relevant values of the " $(\mathrm{Sr}+\mathrm{V})) / \mathrm{O}_{\text {ox }}$ " ratio associated to the excess of vanadium indicates that the surface is cleaned from all Sr-rich phases stated before. It also justifies that the treatment in water implies hydrated vanadium species, "V-OH" on a $\mathrm{VO}_{2}$ terminated surface.

In order to emphasize the last results discussed, the quantitative evolution of the different components with $\theta$ is discussed. Figures 9a., 9b., and 9c., show the relative proportions of the chemical environments present in $\mathrm{Sr} 3 \mathrm{~d}, \mathrm{~V} 2 \mathrm{p}_{3 / 2}$, and $\mathrm{O} 1 \mathrm{~s}$, respectively. Firstly, a decrease of the " $\mathrm{Sr}_{3} \mathrm{~d}_{5 / 2}(\mathrm{SVO})$ " component can be observed (figure 9a.) from $68 \%$ at $0^{\circ}$ to $56 \%$ at $70^{\circ}$, which is related to the increase of the " $\mathrm{Sr} 3 \mathrm{~d}_{5 / 2}(\mathrm{Sr}-\mathrm{O})$ " contribution. The proportion of this latter appears well below the one represented for as-grown SVO before treatment in water (figure 5a.). " $\mathrm{Sr} 3 \mathrm{~d}_{5 / 2}(\mathrm{Sr}-\mathrm{O})$ )" is still detected at the surface since it is mainly due to $\mathrm{SrOH}$ species at this step. Evolution of the $\mathrm{V} 2 \mathrm{p}_{3 / 2}$ contributions can then be observed in figure $9 \mathrm{~b}$.. It shows the general decrease of the "V2 $\mathrm{p}_{3 / 2}(5+),(4+)$, and (3+)" associated to SVO, conversely to the increase of the "V2 $\mathrm{p}_{3 / 2}(\mathrm{~V}-\mathrm{OH})$ " component from $33 \%$ at $0^{\circ}$ to $43 \%$ at $70^{\circ}$. $\mathrm{V}-\mathrm{OH}$ hydroxide species are evidenced on top surface. Finally, we observed the evolution of the O1s contributions in figure 9c.. A slight decrease of "O1s (lattice SVO)" from $34 \%$ at $0^{\circ}$ to $24 \%$ at 
$70^{\circ}$ is found while the "O1s $(\mathrm{O}-\mathrm{C}, \mathrm{O}-\mathrm{H})$ " increases from $20 \%$ at $0^{\circ}$ to $32 \%$ at $70^{\circ}$. The other two components, "O1s (surface SVO)" and "O1s (O-M)" are both readily constant with an average of $21 \%$ and $25 \% \pm 2 \%$, respectively. Such results indicate that the surface of SVO after treatment in water is now governed by a very thin layer of hydroxide species $\mathrm{Sr}-\mathrm{OH}$ and $\mathrm{V}-\mathrm{OH}$, since SVO matrix signal is much more intense. Once more, SVO is still "buried" but the screening effect of the effective XPS signature of the perovskite oxide by the upper layers is weaker after the treatment in water.

Quantitative data for the XPS chemical composition at normal incidence are gathered in table 3. Quantities of $\mathrm{Sr}-\mathrm{OH}$ and $\mathrm{V}-\mathrm{OH}$ are close: 4.2 vs. 4.5 at.\% The perovskite oxide chemical composition is also confirmed with an atomic proportion of Sr3d in SVO of $8.8 \pm 0.1$ at. $\%$, the one of vanadium attributed to SVO of $9.2 \pm 0.1$ at. $\%$. Oxygen quantity $(27.8 \%$ for lattice and surface SVO) is also consistent with stoichiometric SVO.

Thus, our model evidences the efficiency of the treatment in water by revealing: (1) a solubilisation of the Sr-rich phases associated to $\mathrm{SrO}$ species previously in excess at the surface, (2) a surface governed by hydroxides species $\mathrm{Sr}-\mathrm{OH}$ and $\mathrm{V}-\mathrm{OH}$ with a dominant V-OH termination, which represents an electronical asset, and (3) an apparent stoichiometry not only evidenced by global ratios of $\mathrm{Sr} / \mathrm{V}=1.0$ and $(\mathrm{Sr}+\mathrm{V}) / \mathrm{O}_{\mathrm{ox}}=0.67$, but also by the fitting procedure with an equal proportion of $\mathrm{Sr}-\mathrm{OH}$ and $\mathrm{V}-\mathrm{OH}$ species (for $\theta=0^{\circ}$ ) which is in agreement with the hydrolysis reaction of SVO stated below.

\section{Surface reactivity of $\mathrm{SrVO}_{3}$ through air ageing}

Considering the strong reactivity of strontium oxide with carbon and humidity coming from air, we present in this last section of the paper a focus on SVO thin film evolution through different aging time in ambient air. It appears crucial to be aware of the chemical reactions that could disturb or screen the effective spectral response of such thin films. 
Figures 10a and 10b., show the evolution in time of Sr3d, V2p and O1s high energy resolution spectra, respectively, and their reconstruction using our systematic fitting procedure. The XPS signature of (1) as-grown SVO, (2) SVO after 3 months-ageing, (3) SVO after 6 months-ageing, and (4) SVO treated with water after ageing, can thus be compared.

As previously described in part I, as-grown SVO presents two components in the $\mathrm{Sr} 3 \mathrm{~d}$ region ("Sr (SVO)" and "Sr (Sr-O)"), a multi-valence in the $\mathrm{V} 2 \mathrm{p}_{3 / 2}$ region $\left(\mathrm{V}^{5+}, \mathrm{V}^{4+}\right.$, and $\left.\mathrm{V}^{3+}\right)$, and different components in the O1s region ("O (SVO)" from lattice and surface SVO, "O $(\mathrm{O}-$ $\mathrm{M})$ " from single oxide and hydroxide, and "O (O-C, O-H)" from physisorbed carbon species).

After air-ageing for 3 months, a new doublet must be added to the as-grown SVO reconstruction in the $\mathrm{Sr} 3 \mathrm{~d}$ region to fit the measured spectrum (figure 10a. second spectrum from the bottom). This component is settled at a BE of $134.2 \mathrm{eV}$ for $\mathrm{Sr}_{3} \mathrm{~d}_{5 / 2}$ with a FWHM of $1.45 \mathrm{eV}$. Its fitting parameters can be seen as a positive BE shift of $1.55 \pm 0.05 \mathrm{eV}$ from the $\mathrm{Sr}_{3} \mathrm{~d}_{5 / 2}(\mathrm{SVO})$ component. Such new component can be related to the one around $533.0 \mathrm{eV}$ in the $\mathrm{O} 1 \mathrm{~s}$ region (figure 10b.). These two components can be assessed to strontium carbonates "Sr-O$\left(-\mathrm{CO}_{2}\right)$ ", in relation with the associated $\mathrm{C} 1 \mathrm{~s}$ spectral signature (see figure $\mathbf{S} 4$ in supplementary information). The physisorbed species in $\mathrm{O} 1 \mathrm{~s}$ region ("O $(\mathrm{O}-\mathrm{C}, \mathrm{O}-\mathrm{H})$ " component) also increase after 3 months under ambient atmosphere. This is consistent with a carbonation of the Sr-rich phases surface since $\mathrm{SrO}$ single oxide is known for its strong affinity with carbon dioxide $[40,60,61]$.

Another effect of the air-ageing is the increase of the various surface components " $\mathrm{Sr}$ (Sr-O)", "V5+", and "O (O-M)" in opposition to the bulk SVO oxide. This general observation is even more noticeable in the 6 months air-aged SVO sample spectral responses. In this case, "Sr (SVO)" as well as the O1s component related to SVO phase ("O (SVO)") and the "V ${ }^{3+"}$ components are below the detection limit of XPS. Only a very weak "V ${ }^{4+}$ " signature is still observed. Conversely, the "Sr ( $\mathrm{Sr}-\mathrm{O})$ )" and the "V ${ }^{5+}$ " components are predominant. A possible 
explanation of this trend is a screening effect due to a consequent amount of Sr-rich compounds deposited on top of SVO because of its reactivity/affinity with carbon species coming from of organic contamination. Then, the ageing certainly implies a significant surface reactivity due to air oxidation which tend to extend inside the layer with the time, following the general oxidation reaction: $2 \mathrm{SrVO}_{3}+1 / 2 \mathrm{O}_{2} \rightarrow 2 \mathrm{SrO}+\mathrm{V}_{2} \mathrm{O}_{5}$.

The last spectra on top of the figures 10a. and 10b. correspond to the surface obtained after rinsing the aged $\mathrm{SVO}$ with water. The spectral signature of such $\mathrm{H}_{2} \mathrm{O}$-treated $\mathrm{SVO}$ shows similar results to the one obtained on as-grown SVO rinsed in water and presented in section II. The detailed high energy resolution spectra of the regions of interest, AR-XPS data, evolutions of global ratios, relative proportions of the different chemical environments, and also estimation of the chemical composition of this case are presented in supplementary information in figures S5 to S8, and in table S1, respectively. As figures 6 to 9 can be directly transposed to figures S5 to S8, these results are a matter of importance by proving the efficiency of the treatment in water independently of the ageing time. Indeed, we demonstrate here the ability to recover SVO surface and its specific XPS spectral signature using only dissolution of surface layers in water.

Such achievement is crucial as the rinsing represent a necessary step to obtain a reproducible starting point for upcoming deposition on the surface. In order to go further and estimate the lifetime of the reproducible steady-state, the influence of air-ageing on a $\mathrm{H}_{2} \mathrm{O}$ treated SVO has been studied. Thus, different air-ageing duration after rinsing are considered: 12 hours, 3 days, 6 days, and 3 months, where the respective spectral line evolutions of the $\mathrm{Sr} 3 \mathrm{~d}, \mathrm{~V} 2 \mathrm{p}_{3 / 2}$, and $\mathrm{O} 1 \mathrm{~s}$ regions are presented in figures 11a., 11b., and 11c.. The general signal evolution through this air-ageing is similar to the one described in figures $\mathbf{1 0}$. The components assessed to SVO oxide: "Sr (SVO)", "O (SVO)" with the usual multi-valence of V (V ${ }^{5+}, \mathrm{V}^{4+}$, and $\left.\mathrm{V}^{3+}\right)$, are progressively screened by secondary surface phases such as " $\mathrm{Sr}(\mathrm{Sr}-\mathrm{O})$ ", " $\mathrm{V}^{5+"}$, 
"O $(\mathrm{O}-\mathrm{M})$ ", and organic species "O $(\mathrm{O}-\mathrm{C}, \mathrm{O}-\mathrm{H})$ ". However, the kinetics of the air-ageing effects was considerably increased in this case. Indeed, from a XPS point of view, a typical "intermediate" state between as-grown and the 6 months-old samples can be observed for 3 months ageing in figures 10, whereas such "intermediate" state, between a major SVO signature and a totally screened one, is observed between only 3 and 6 days of air-ageing after treatment in water in figures 11.

In order to highlight this phenomenon, the proportion of strontium secondary species in Sr3d spectral region ("Sr-O" and "Sr-O(- $\left.\mathrm{CO}_{2}\right)$ " components) has been reported as a function of air-ageing time in figure 12. Before air-ageing, the samples with the lowest amount of $\mathrm{SrO}$ secondary species are the ones rinsed with water ("Aged SVO" and "As-grown SVO" after $\mathrm{H}_{2} \mathrm{O}$ ), showing the efficiency of our treatment. Then, the air-ageing is reported for the different cases shown in figures $\mathbf{1 0}$ and $\mathbf{1 1}$. It evidences again that an air-ageing of 3 months of an asgrown SVO is similar to an air-ageing of only few days (from 3 to 6 days) after the treatment in water. We can finally conclude that hydrolyzed SVO surfaces present a higher chemical reactivity likely due to their - $\mathrm{OH}$ surface terminations. The treatment in water was found very efficient to remove Sr-rich phases in excess from SVO surface and other oxygen-rich phases containing $\mathrm{V}^{5+}$ species. However, the reader should be aware that such hydrolyzed surface presents an enhanced chemical reactivity and thus requires an efficient passivation process. Some perovskite oxides such as $\mathrm{LaAlO}_{3}$ has already been used [42], but more common capping oxides such as $\mathrm{Al}_{2} \mathrm{O}_{3}$, or organic capping layer such as poly(methyl-methacrylate [62] or polystyrene [63] have to be investigated. 


\section{CONCLUSION}

In this work, we perform an angle-resolved X-ray photoelectron spectroscopy study on promising functional perovskite oxide thin films of $\mathrm{SrVO}_{3}$ (SVO). Combining the deconvolution of $\mathrm{Sr} 3 \mathrm{~d}, \mathrm{~V} 2 \mathrm{p}_{3 / 2}$ and $\mathrm{O} 1 \mathrm{~s}$ spectral regions of interest, our systematic fitting procedure clearly indicates the different chemical environments observed at the surface of "asgrown" SVO thin films by giving from surface to volume: (1) physisorbed species coming from air contamination, (2) Sr-rich phases assigned to single oxide $\mathrm{SrO}$ and overoxidized $\mathrm{V}^{5+}$ vanadium states, and (3) the expected bulk SVO thin film close to $\mathrm{SrVO}_{3}$ stoichiometry. This deconvolution leads to a more accurate $\mathrm{Sr} / \mathrm{V}$ ratio calculation. Sr-rich surface layer, probably due to Sr segregation during the cooling of the PLD growth process, can be evaluated at least in the first three nanometers using depth profiling. This thin layer presents a different electrical conductivity than bulk SVO and can influence for example the metal to insulator transition with reducing the SVO film thickness. Hopefully, Sr-rich phases can be readily removed using an efficient $\mathrm{H}_{2} \mathrm{O}$-treatment, releasing the stoichiometric bulk $\mathrm{SrVO}_{3}$ phase. The resulting " $\mathrm{H}_{2} \mathrm{O}$ treated" SVO surface appears more electrically active due to $\mathrm{VO}_{2}$-terminations. However, such hydrolyzed surfaces are more sensitive and reactive as demonstrated in the comparative study between "as-grown" and " $\mathrm{H}_{2} \mathrm{O}$-treated" $\mathrm{SVO}$ through air-aging. One should take under consideration that special processes for passivation or diffusion barrier inorganic or organic capping need to be developed at a short time after releasing Sr-rich phases in water, in order to use SVO as an active functional layer in future electronic devices. 


\section{AUTHOR INFORMATION}

\section{Corresponding Authors}

Yoan BOURLIER *yoan.bourlier@uvsq.fr

Damien AUREAU *damien.aureau@uvsq.fr

\section{ACKNOWLEDGMENT}

The authors thank the Labex CHARMMMAT (ANR-11-LABEX-0039) from IDEX Paris-Saclay, and the French Agence Nationale de la Recherche (ANR) in the framework of the POLYNASH project (ANR-17-CE08-0012) for their financial support. The authors are also thankful for Dr. O. Popova for the preparation of the $\mathrm{PLD} \mathrm{SrVO}_{3}(\mathrm{SVO})$ target. 


\section{REFERENCES}

[1] M.C. Biesinger, B.P. Payne, A.P. Grosvenor, L.W.M. Lau, A.R. Gerson, R.St.C. Smart, Resolving surface chemical states in XPS analysis of first row transition metals, oxides and hydroxides: Cr, $\mathrm{Mn}, \mathrm{Fe}, \mathrm{Co}$ and $\mathrm{Ni}$, Applied Surface Science. 257 (2011) 2717-2730. https://doi.org/10.1016/j.apsusc.2010.10.051.

[2] T. Yamashita, P. Hayes, Analysis of XPS spectra of $\mathrm{Fe}^{2+}$ and $\mathrm{Fe}^{3+}$ ions in oxide materials, Applied Surface Science. 254 (2008) 2441-2449. https://doi.org/10.1016/j.apsusc.2007.09.063.

[3] C.R. Brundle, G. Conti, P. Mack, XPS and angle resolved XPS, in the semiconductor industry: Characterization and metrology control of ultra-thin films, Journal of Electron Spectroscopy and Related Phenomena. 178-179 (2010) 433-448. https://doi.org/10.1016/j.elspec.2010.03.008.

[4] S. Kaciulis, E. Bolli, A. Mezzi, M. Vagner, V. Plausinaitiene, S. Kersulis, N. Zurauskiene, R. Lukose, Surface and structural analysis of epitaxial $\mathrm{La}_{1-\mathrm{x}} \mathrm{Sr}_{\mathrm{x}}\left(\mathrm{Mn}_{1-\mathrm{y}} \mathrm{Co}_{\mathrm{y}}\right)_{\mathrm{z}} \mathrm{O}_{3}$ films, Surface and Interface Analysis. n/a (n.d.). https://doi.org/10.1002/sia.6767.

[5] J.B. Goodenough, Electronic and ionic transport properties and other physical aspects of perovskites, Rep. Prog. Phys. 67 (2004) 1915-1993. https://doi.org/10.1088/0034-4885/67/11/R01.

[6] J. Heber, Materials science: Enter the oxides, Nature. 459 (2009) 28-30. https://doi.org/10.1038/459028a.

[7] M. Coll, J. Fontcuberta, M. Althammer, M. Bibes, H. Boschker, A. Calleja, G. Cheng, M. Cuoco, R. Dittmann, B. Dkhil, I. El Baggari, M. Fanciulli, I. Fina, E. Fortunato, C. Frontera, S. Fujita, V. Garcia, S.T.B. Goennenwein, C.-G. Granqvist, J. Grollier, R. Gross, A. Hagfeldt, G. Herranz, K. Hono, E. Houwman, M. Huijben, A. Kalaboukhov, D.J. Keeble, G. Koster, L.F. Kourkoutis, J. Levy, M. Lira-Cantu, J.L. MacManus-Driscoll, J. Mannhart, R. Martins, S. Menzel, T. Mikolajick, M. Napari, M.D. Nguyen, G. Niklasson, C. Paillard, S. Panigrahi, G. Rijnders, F. Sánchez, P. Sanchis, S. Sanna, D.G. Schlom, U. Schroeder, K.M. Shen, A. Siemon, M. Spreitzer, H. Sukegawa, R. Tamayo, J. van den Brink, N. Pryds, F.M. Granozio, Towards Oxide Electronics: a Roadmap, Applied Surface Science. 482 (2019) 1-93. https://doi.org/10.1016/j.apsusc.2019.03.312.

[8] A. Ohtomo, H.Y. Hwang, A high-mobility electron gas at the LaAlO 3 /SrTiO 3 heterointerface, Nature. 427 (2004) 423-426. https://doi.org/10.1038/nature02308.

[9] J. Mannhart, D.G. Schlom, Oxide Interfaces-An Opportunity for Electronics, Science. 327 (2010) 1607-1611. https://doi.org/10.1126/science.1181862.

[10]S.A. Chambers, M.H. Engelhard, V. Shutthanandan, Z. Zhu, T.C. Droubay, L. Qiao, P.V. Sushko, T. Feng, H.D. Lee, T. Gustafsson, E. Garfunkel, A.B. Shah, J.-M. Zuo, Q.M. Ramasse, Instability, intermixing and electronic structure at the epitaxial $\mathrm{LaAlO}_{3} / \mathrm{SrTiO}_{3}(001)$ heterojunction, Surface Science Reports. 65 (2010) 317-352. https://doi.org/10.1016/j.surfrep.2010.09.001.

[11]K. Ridier, D. Aureau, B. Bérini, Y. Dumont, N. Keller, J. Vigneron, A. Etcheberry, B. Domengès, A. Fouchet, Tuning the electronic properties of $\mathrm{LaAlO}_{3} / \mathrm{SrTiO}_{3}$ interfaces by irradiating the $\mathrm{LaAlO}_{3}$ surface with low-energy cluster ion beams, Phys. Rev. B. 97 (2018) 035146. https://doi.org/10.1103/PhysRevB.97.035146.

[12]S. Itoh, Electronic structure of $\mathrm{SrVO}_{3}$, Solid State Communications. 88 (1993) 525-527. https://doi.org/10.1016/0038-1098(93)90042-L.

[13]S.Q. Hui, A. Petric, Conductivity and stability of $\mathrm{SrVO}_{3}$ and mixed perovskites at low oxygen partial pressures, Solid State Ionics. 143 (2001) 275-283. https://doi.org/10.1016/S0167-2738(01)008700 .

[14]R. Jacobs, J. Booske, D. Morgan, Understanding and Controlling the Work Function of Perovskite Oxides Using Density Functional Theory, Advanced Functional Materials. 26 (2016) 5471-5482. https://doi.org/10.1002/adfm.201600243.

[15]M. Casula, A. Rubtsov, S. Biermann, Dynamical screening effects in correlated materials: Plasmon satellites and spectral weight transfers from a Green's function ansatz to extended dynamical mean field theory, Phys. Rev. B. 85 (2012) 035115. https://doi.org/10.1103/PhysRevB.85.035115. 
[16]J.M. Tomczak, M. Casula, T. Miyake, F. Aryasetiawan, S. Biermann, Combined GW and dynamical mean-field theory: Dynamical screening effects in transition metal oxides, EPL. 100 (2012) 67001. https://doi.org/10.1209/0295-5075/100/67001.

[17] S. Backes, T.C. Rödel, F. Fortuna, E. Frantzeskakis, P. Le Fèvre, F. Bertran, M. Kobayashi, R. Yukawa, T. Mitsuhashi, M. Kitamura, K. Horiba, H. Kumigashira, R. Saint-Martin, A. Fouchet, B. Berini, Y. Dumont, A.J. Kim, F. Lechermann, H.O. Jeschke, M.J. Rozenberg, R. Valentí, A.F. Santander-Syro, Hubbard band versus oxygen vacancy states in the correlated electron metal SrVO3, Phys. Rev. B. 94 (2016) 241110. https://doi.org/10.1103/PhysRevB.94.241110.

[18]L. Zhang, Y. Zhou, L. Guo, W. Zhao, A. Barnes, H.-T. Zhang, C. Eaton, Y. Zheng, M. Brahlek, H.F. Haneef, N.J. Podraza, M.H.W. Chan, V. Gopalan, K.M. Rabe, R. Engel-Herbert, Correlated metals as transparent conductors, Nature Materials. 15 (2016) 204-+. https://doi.org/10.1038/NMAT4493.

[19] M. Mirjolet, F. Sánchez, J. Fontcuberta, High Carrier Mobility, Electrical Conductivity, and Optical Transmittance in Epitaxial $\mathrm{SrVO}_{3}$ Thin Films, Advanced Functional Materials. 29 (2019) 1808432. https://doi.org/10.1002/adfm.201808432.

[20]M. Brahlek, L. Zhang, C. Eaton, H.-T. Zhang, R. Engel-Herbert, Accessing a growth window for $\mathrm{SrVO}_{3}$ thin films, Appl. Phys. Lett. 107 (2015) 143108. https://doi.org/10.1063/1.4932198.

[21]Y. Bourlier, B. Bérini, M. Frégnaux, A. Fouchet, D. Aureau, Y. Dumont, Transfer of Epitaxial $\mathrm{SrTiO}_{3}$ Nanothick Layers Using Water-Soluble Sacrificial Perovskite Oxides, ACS Appl. Mater. Interfaces. 12 (2020) 8466-8474. https://doi.org/10.1021/acsami.9b21047.

[22]B. Berini, V. Demange, M. Bouttemy, E. Popova, N. Keller, Y. Dumont, A. Fouchet, Control of High Quality $\mathrm{SrVO}_{3}$ Electrode in Oxidizing Atmosphere, Advanced Materials Interfaces. 3 (2016) 1600274. https://doi.org/10.1002/admi.201600274.

[23] R.C. Germanicus, Y. Bourlier, V. Notot, B. Bérini, V. Demange, M. Berthe, A. Boileau, M. Euchin, Y. Dumont, D. Aureau, M. Fregnaux, B. Grandidier, U. Lüders, A. David, W. Prellier, L. Biadala, A. Fouchet, Three dimensional resistance mapping of self-organized $\mathrm{Sr}_{3} \mathrm{~V}_{2} \mathrm{O}_{8}$ nanorods on metallic perovskite $\mathrm{SrVO}_{3}$ matrix, Applied Surface Science. $510 \quad$ (2020) 145522. https://doi.org/10.1016/j.apsusc.2020.145522.

[24]J.A. Moyer, C. Eaton, R. Engel-Herbert, Highly Conductive $\mathrm{SrVO}_{3}$ as a Bottom Electrode for Functional Perovskite Oxides, Advanced Materials. $25 \quad$ (2013) 3578-3582. https://doi.org/10.1002/adma.201300900.

[25]D. Aureau, K. Ridier, B. Bérini, Y. Dumont, N. Keller, J. Vigneron, M. Bouttemy, A. Etcheberry, A. Fouchet, Advanced analysis tool for X-ray photoelectron spectroscopy profiling: Cleaning of perovskite $\mathrm{SrTiO}_{3}$ oxide surface using argon cluster ion source, Thin Solid Films. 601 (2016) 8992. https://doi.org/10.1016/j.tsf.2015.11.017.

[26]K. Ridier, D. Aureau, B. Bérini, Y. Dumont, N. Keller, J. Vigneron, A. Etcheberry, A. Fouchet, Enhanced Depth Profiling of Perovskite Oxide: Low Defect Levels Induced in $\mathrm{SrTiO}_{3}$ by Argon Cluster Sputtering, J. Phys. Chem. C. 120 (2016) 21358-21363. https://doi.org/10.1021/acs.jpcc.6b04007.

[27]M.C. Biesinger, L.W.M. Lau, A.R. Gerson, R.St.C. Smart, Resolving surface chemical states in XPS analysis of first row transition metals, oxides and hydroxides: $\mathrm{Sc}, \mathrm{Ti}, \mathrm{V}, \mathrm{Cu}$ and $\mathrm{Zn}$, Applied Surface Science. 257 (2010) 887-898. https://doi.org/10.1016/j.apsusc.2010.07.086.

[28]G. Silversmit, D. Depla, H. Poelman, G.B. Marin, R. De Gryse, Determination of the V2p XPS binding energies for different vanadium oxidation states $\left(\mathrm{V}^{5+}\right.$ to $\left.\mathrm{V}^{0+}\right)$, Journal of Electron Spectroscopy and Related Phenomena. 135 (2004) 167-175. https://doi.org/10.1016/j.elspec.2004.03.004.

[29]M.C. Biesinger, B.P. Payne, L.W.M. Lau, A. Gerson, R.S.C. Smart, X-ray photoelectron spectroscopic chemical state quantification of mixed nickel metal, oxide and hydroxide systems, Surface and Interface Analysis. 41 (2009) 324-332. https://doi.org/10.1002/sia.3026.

[30]D.R. Baer, K. Artyushkova, C. Richard Brundle, J.E. Castle, M.H. Engelhard, K.J. Gaskell, J.T. Grant, R.T. Haasch, M.R. Linford, C.J. Powell, A.G. Shard, P.M.A. Sherwood, V.S. Smentkowski, Practical guides for $\mathrm{x}$-ray photoelectron spectroscopy: First steps in planning, conducting, and reporting XPS measurements, Journal of Vacuum Science \& Technology A. 37 (2019) 031401. https://doi.org/10.1116/1.5065501. 
[31]G. Greczynski, L. Hultman, X-ray photoelectron spectroscopy: Towards reliable binding energy referencing, Progress in Materials Science. $107 \quad$ (2020) 100591. https://doi.org/10.1016/j.pmatsci.2019.100591.

[32] A. Ito, H. Masumoto, T. Goto, Microstructure and Electrical Conductivity of Epitaxial $\mathrm{SrRuO}_{3}$ Thin Films Prepared on (001), (110) and (111) $\mathrm{SrTiO}_{3}$ Substrates by Laser Ablation, Materials Transactions. 48 (2007) 227-233. https://doi.org/10.2320/matertrans.48.227.

[33]W.T. Hong, K.A. Stoerzinger, E.J. Crumlin, E. Mutoro, H. Jeen, H.N. Lee, Y. Shao-Horn, NearAmbient Pressure XPS of High-Temperature Surface Chemistry in $\mathrm{Sr}_{2} \mathrm{Co}_{2} \mathrm{O}_{5}$ Thin Films, Top Catal. 59 (2016) 574-582. https://doi.org/10.1007/s11244-015-0532-4.

[34]E.J. Crumlin, E. Mutoro, Z. Liu, M.E. Grass, M.D. Biegalski, Y.-L. Lee, D. Morgan, H.M. Christen, H. Bluhm, Y. Shao-Horn, Surface strontium enrichment on highly active perovskites for oxygen electrocatalysis in solid oxide fuel cells, Energy Environ. Sci. 5 (2012) 6081-6088. https://doi.org/10.1039/C2EE03397F.

[35]E.J. Crumlin, E. Mutoro, W.T. Hong, M.D. Biegalski, H.M. Christen, Z. Liu, H. Bluhm, Y. ShaoHorn, In Situ Ambient Pressure X-ray Photoelectron Spectroscopy of Cobalt Perovskite Surfaces under Cathodic Polarization at High Temperatures, J. Phys. Chem. C. 117 (2013) 16087-16094. https://doi.org/10.1021/jp4051963.

[36]A.K. Opitz, C. Rameshan, M. Kubicek, G.M. Rupp, A. Nenning, T. Götsch, R. Blume, M. Hävecker, A. Knop-Gericke, G. Rupprechter, B. Klötzer, J. Fleig, The Chemical Evolution of the $\mathrm{La}_{0.6} \mathrm{Sr}_{0.4} \mathrm{CoO}_{3-\delta}$ Surface Under SOFC Operating Conditions and Its Implications for Electrochemical Oxygen Exchange Activity, Top Catal. 61 (2018) 2129-2141. https://doi.org/10.1007/s11244-018-1068-1.

[37]D. Dogu, K.E. Meyer, A. Fuller, S. Gunduz, D.J. Deka, N. Kramer, A.C. Co, U.S. Ozkan, Effect of lanthanum and chlorine doping on strontium titanates for the electrocatalytically-assisted oxidative dehydrogenation of ethane, Applied Catalysis B: Environmental. 227 (2018) 90-101. https://doi.org/10.1016/j.apcatb.2018.01.019.

[38]J. Kuyyalil, D. Newby, J. Laverock, Y. Yu, D. Cetin, S.N. Basu, K. Ludwig, K.E. Smith, Vacancy assisted $\mathrm{SrO}$ formation on $\mathrm{La}_{0.8} \mathrm{Sr}_{0.2} \mathrm{Co}_{0.2} \mathrm{Fe}_{0.8} \mathrm{O}_{3-\delta}$ surfaces-A synchrotron photoemission study, Surface Science. 642 (2015) 33-38. https://doi.org/10.1016/j.susc.2015.08.001.

[39] C. Lin, A. Posadas, T. Hadamek, A.A. Demkov, Final-state effect on x-ray photoelectron spectrum of nominally $\mathrm{d}^{1}$ and $\mathrm{n}$-doped $\mathrm{d}^{0}$ transition-metal oxides, Phys. Rev. B. 92 (2015) 035110. https://doi.org/10.1103/PhysRevB.92.035110.

[40]P.A.W. van der Heide, Systematic x-ray photoelectron spectroscopic study of La1-xSrx-based perovskite-type oxides, Surface and Interface Analysis. 33 (2002) 414-425. https://doi.org/10.1002/sia.1227.

[41]R.P. Vasquez, X-ray photoelectron spectroscopy study of Sr and Ba compounds, Journal of Electron Spectroscopy and Related Phenomena. 56 (1991) 217-240. https://doi.org/10.1016/03682048(91)85005-E.

[42]A. Fouchet, J.E. Rault, M. Allain, B. Berini, J.-P. Rueff, Y. Dumont, N. Keller, Interface chemical and electronic properties of $\mathrm{LaAlO}_{3} / \mathrm{SrVO}_{3}$ heterostructures, Journal of Applied Physics. 123 (2018) 055302. https://doi.org/10.1063/1.4998004.

[43]E. Hryha, E. Rutqvist, L. Nyborg, Stoichiometric vanadium oxides studied by XPS, Surface and Interface Analysis. 44 (2012) 1022-1025. https://doi.org/10.1002/sia.3844.

[44]F. Ureña-Begara, A. Crunteanu, J.-P. Raskin, Raman and XPS characterization of vanadium oxide thin films with temperature, Applied Surface Science. 403 (2017) 717-727. https://doi.org/10.1016/j.apsusc.2017.01.160.

[45] V. Young, T. Otagawa, XPS studies on strontium compounds, Applications of Surface Science. 20 (1985) 228-248. https://doi.org/10.1016/0378-5963(85)90083-2.

[46]T. Katayama, A. Chikamatsu, K. Yamada, K. Shigematsu, T. Onozuka, M. Minohara, H. Kumigashira, E. Ikenaga, T. Hasegawa, Epitaxial growth and electronic structure of oxyhydride $\mathrm{SrVO} 2 \mathrm{H}$ thin films, Journal of Applied Physics. $120 \quad$ (2016) 085305. https://doi.org/10.1063/1.4961446.

[47]B. Koo, K. Kim, J.K. Kim, H. Kwon, J.W. Han, W. Jung, Sr Segregation in Perovskite Oxides: Why It Happens and How It Exists, Joule. 2 (2018) 1476-1499. https://doi.org/10.1016/j.joule.2018.07.016. 
[48]A. Staykov, H. Tellez, J. Druce, J. Wu, T. Ishihara, J. Kilner, Electronic properties and surface reactivity of SrO-terminated $\mathrm{SrTiO}_{3}$ and SrO-terminated iron-doped $\mathrm{SrTiO}_{3}$, Science and $\begin{array}{llllll}\text { Technology of } & \text { Advanced } & \text { Materials. } & 19 & \text { (2018) }\end{array}$ https://doi.org/10.1080/14686996.2018.1440136.

[49] Y. Bourlier, M. Fregnaux, B. Berini, A. Fouchet, Y. Dumont, D. Aureau, Surface Characterizations and Selective Etching of Sr-Rich Segregation on Top of $\mathrm{SrVO}_{3}$ Thin-Films Grown by Pulsed Laser Deposition, Chemnanomat. 5 (2019) 674-681. https://doi.org/10.1002/cnma.201900017.

[50]J.G. Connell, B.J. Isaac, G.B. Ekanayake, D.R. Strachan, S.S.A. Seo, Preparation of atomically flat $\mathrm{SrTiO}_{3}$ surfaces using a deionized-water leaching and thermal annealing procedure, Appl. Phys. Lett. 101 (2012) 251607. https://doi.org/10.1063/1.4773052.

[51]D. Kobayashi, R. Hashimoto, A. Chikamatsu, H. Kumigashira, M. Oshima, T. Ohnishi, M. Lippmaa, K. Ono, M. Kawasaki, H. Koinuma, Sr surface segregation and water cleaning for atomically controlled $\mathrm{SrTiO}_{3}(001)$ substrates studied by photoemission spectroscopy, Journal of Electron Spectroscopy and Related Phenomena. 144-147 (2005) 443-446. https://doi.org/10.1016/j.elspec.2005.01.167.

[52]G. Koster, B.L. Kropman, G.J.H.M. Rijnders, D.H.A. Blank, H. Rogalla, Quasi-ideal strontium titanate crystal surfaces through formation of strontium hydroxide, Appl. Phys. Lett. 73 (1998) 2920-2922. https://doi.org/10.1063/1.122630.

[53]P.V. Nagarkar, P.C. Searson, F.D. Gealy, Effect of surface treatment on $\mathrm{SrTiO}_{3}$ : An x-ray photoelectron spectroscopic study, Journal of Applied Physics. 69 (1991) 459-462. https://doi.org/10.1063/1.347685.

[54]L. Sygellou, H. Tielens, C. Adelmann, S. Ladas, An X-ray photoelectron spectroscopy study of strontium-titanate-based high-k film stacks, Microelectronic Engineering. 90 (2012) 138-140. https://doi.org/10.1016/j.mee.2011.03.003.

[55]D.J. Michalak, S.R. Amy, D. Aureau, M. Dai, A. Estève, Y.J. Chabal, Nanopatterning Si(111) surfaces as a selective surface-chemistry route, Nature Mater. 9 (2010) 266-271. https://doi.org/10.1038/nmat2611.

[56] V. Singh, P.C. Mondal, A.K. Singh, M. Zharnikov, Molecular sensors confined on SiOx substrates, Coordination Chemistry Reviews. 330 (2017) 144-163. https://doi.org/10.1016/j.ccr.2016.09.015.

[57]A.M. Schrader, J.I. Monroe, R. Sheil, H.A. Dobbs, T.J. Keller, Y. Li, S. Jain, M.S. Shell, J.N. Israelachvili, S. Han, Surface chemical heterogeneity modulates silica surface hydration, PNAS. 115 (2018) 2890-2895. https://doi.org/10.1073/pnas.1722263115.

[58] S.T. Barry, A.V. Teplyakov, F. Zaera, The Chemistry of Inorganic Precursors during the Chemical Deposition of Films on Solid Surfaces, Acc. Chem. Res. 51 (2018) 800-809. https://doi.org/10.1021/acs.accounts.8b00012.

[59]H. Oka, Y. Okada, T. Hitosugi, T. Fukumura, Two distinct surface terminations of $\mathrm{SrVO}_{3}(001)$ ultrathin films as an influential factor on metallicity, Applied Physics Letters. 113 (2018) 171601. https://doi.org/10.1063/1.5051434.

[60]A. Staykov, S. Fukumori, K. Yoshizawa, K. Sato, T. Ishihara, J. Kilner, Interaction of SrOterminated $\mathrm{SrTiO}_{3}$ surface with oxygen, carbon dioxide, and water, J. Mater. Chem. A. 6 (2018) 22662-22672. https://doi.org/10.1039/C8TA05177A.

[61] Y. Yu, H. Luo, D. Cetin, X. Lin, K. Ludwig, U. Pal, S. Gopalan, S. Basu, Effect of atmospheric $\mathrm{CO}_{2}$ on surface segregation and phase formation in $\mathrm{La}_{0.6} \mathrm{Sr}_{0.4} \mathrm{Co}_{0.2} \mathrm{Fe}_{0.8} \mathrm{O}_{3-\delta}$ thin films, Applied Surface Science. 323 (2014) 71-77. https://doi.org/10.1016/j.apsusc.2014.09.019.

[62]J. Peng, J.I. Khan, W. Liu, E. Ugur, T. Duong, Y. Wu, H. Shen, K. Wang, H. Dang, E. Aydin, X. Yang, Y. Wan, K.J. Weber, K.R. Catchpole, F. Laquai, S.D. Wolf, T.P. White, A Universal DoubleSide Passivation for High Open-Circuit Voltage in Perovskite Solar Cells: Role of Carbonyl Groups in Poly(methyl methacrylate), Advanced Energy Materials. 8 (2018) 1801208. https://doi.org/10.1002/aenm.201801208.

[63]T. Wang, Z. Cheng, Y. Zhou, H. Liu, W. Shen, Highly efficient and stable perovskite solar cells via bilateral passivation layers, J. Mater. Chem. A. 7 (2019) 21730-21739. https://doi.org/10.1039/C9TA08084H. 


\section{GRAPHICAL ABSTRACT}

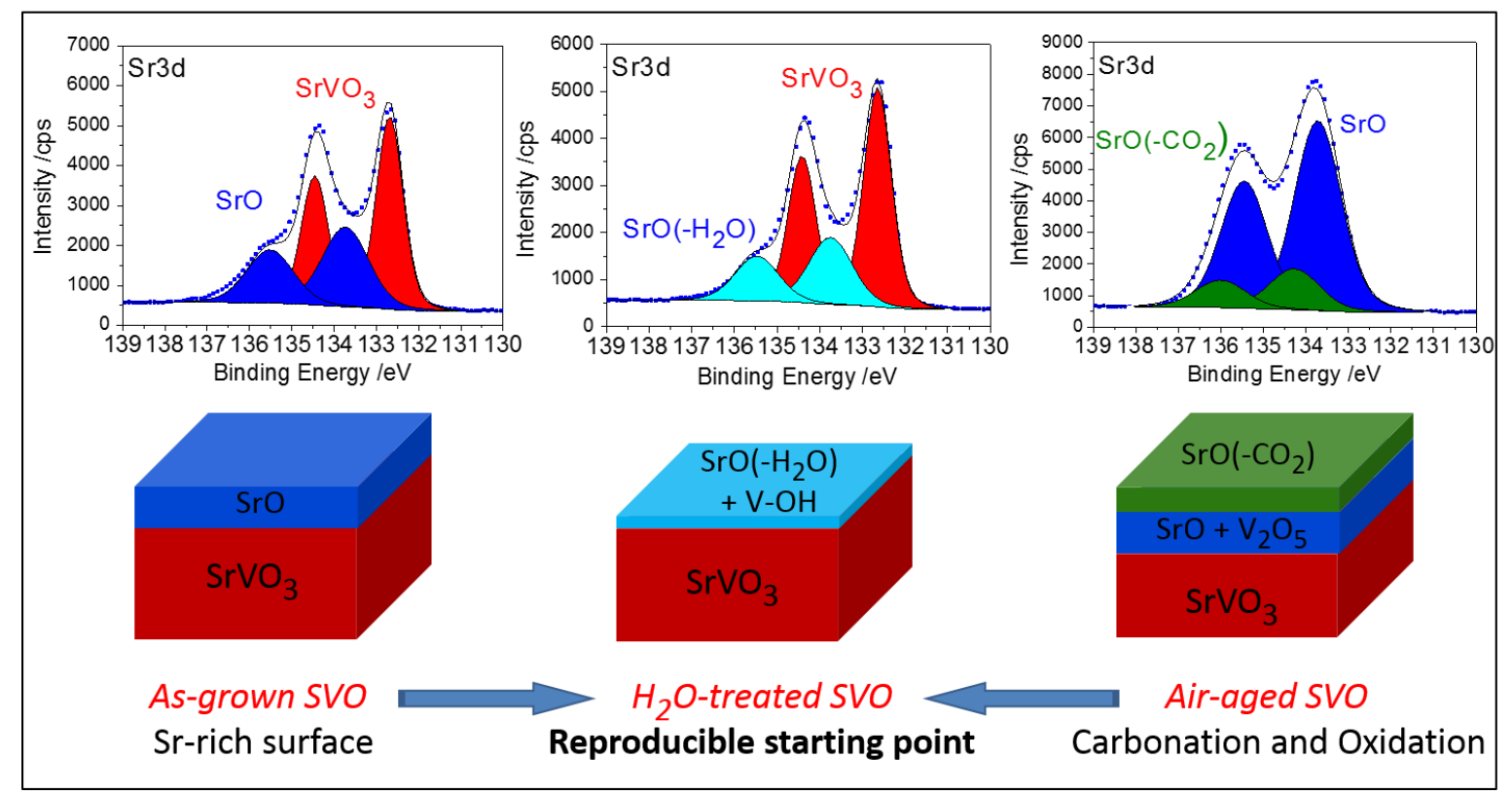

\section{HIGHLIGHTS}

- Sr-rich phases onto $\mathrm{SrVO}_{3}$ thin films are studied using Angle Resolved XPS

- A treatment in water removes $\mathrm{Sr}$ excess by giving a V-OH terminated surface

- A study of air-ageing onto "as-grown" and " $\mathrm{H}_{2} \mathrm{O}$-treated" $\mathrm{SVO}$ is finally pursued 


\section{FIGURES AND TABLES:}

\section{I/ As-grown SVO}

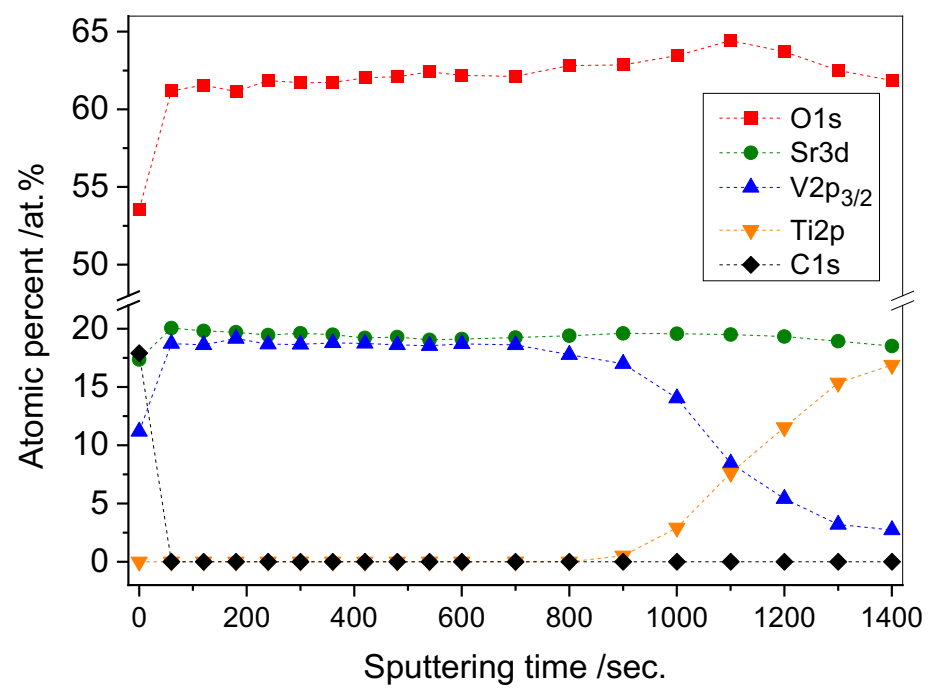

Figure 1: XPS monoatomic $\mathrm{Ar}^{+}$depth profiling of an as-grown SVO thin film of $40 \mathrm{~nm}-$ thick (energy $4000 \mathrm{eV}$ ).
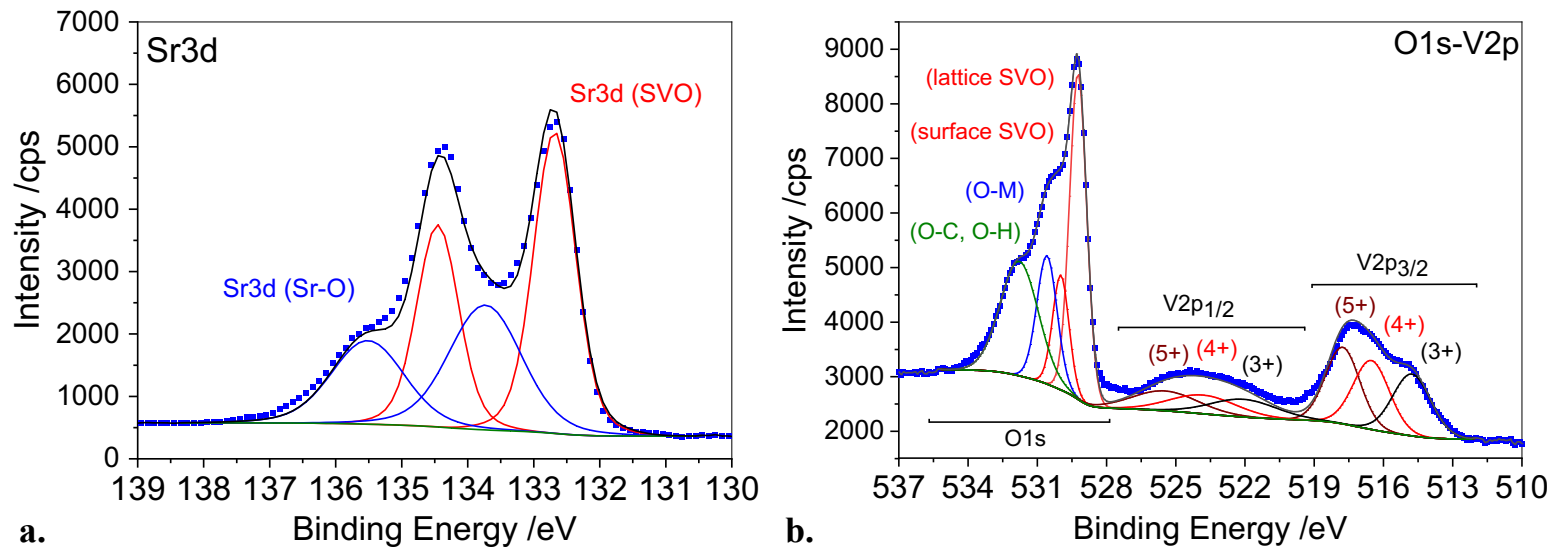

Figure 2: High energy resolution spectra of a. O1s-V2p and b. Sr3d regions with chemical environments attributed to the analysed as-grown SVO at normal incidence. 


\begin{tabular}{|c|c|c|c|}
\hline Name & BE $(\mathrm{eV})$ & FWHM (eV) & Peak attributions \\
\hline $\operatorname{Sr3d}_{5 / 2}(\mathrm{SVO})$ & $132.7( \pm 0.1)$ & $0.7-0.8$ & perovskite \\
\hline $\operatorname{Sr} d_{5 / 2}(\operatorname{Sr}-O)$ & $\mathrm{BE}+1.10 \mathrm{eV}( \pm 0.05)$ & $1.2-1.3$ & surface oxide or hydroxide \\
\hline$V 2 p_{3 / 2}(5+)$ & $517.7( \pm 0.1)$ & $1.7-1.8$ & $\mathrm{~V}^{5+}$ oxidation state \\
\hline$V 2 p_{3 / 2}(4+)$ & $\mathrm{BE}-1.25 \mathrm{eV}( \pm 0.05)$ & $1.8-1.9$ & $V^{4+}$ oxidation state \\
\hline$V 2 p_{3 / 2}(3+)$ & $\mathrm{BE}-3.00 \mathrm{eV}( \pm 0.05)$ & $1.9-2.0$ & $V^{3+}$ oxidation state \\
\hline O1s (lattice SVO) & $529.2( \pm 0.1)$ & $0.8-0.9$ & lattice perovskite \\
\hline O1s (surface SVO) & $\mathrm{BE}+0.80 \mathrm{eV}( \pm 0.05)$ & $0.8-0.9$ & surface perovskite \\
\hline O1s (O-M) & $\mathrm{BE}+1.40 \mathrm{eV}( \pm 0.05)$ & $1.0-1.1$ & metal oxide hydroxide \\
\hline O1s (O-C. O-H) & $\mathrm{BE}+2.50 \mathrm{eV}( \pm 0.05)$ & $1.8-2.0$ & physisorbed species \\
\hline C1s & $284.8-285.0$ & $>1.0$ & physisorbed species \\
\hline
\end{tabular}

Table 1: Peak attributions of the different chemical elements at the surface of SVO thin films and their related Binding Energy (BE), Full Width at Half Maximum (FWHM), and enforced fitting parameters, corresponding to the fitting procedure (associated to figure 2).
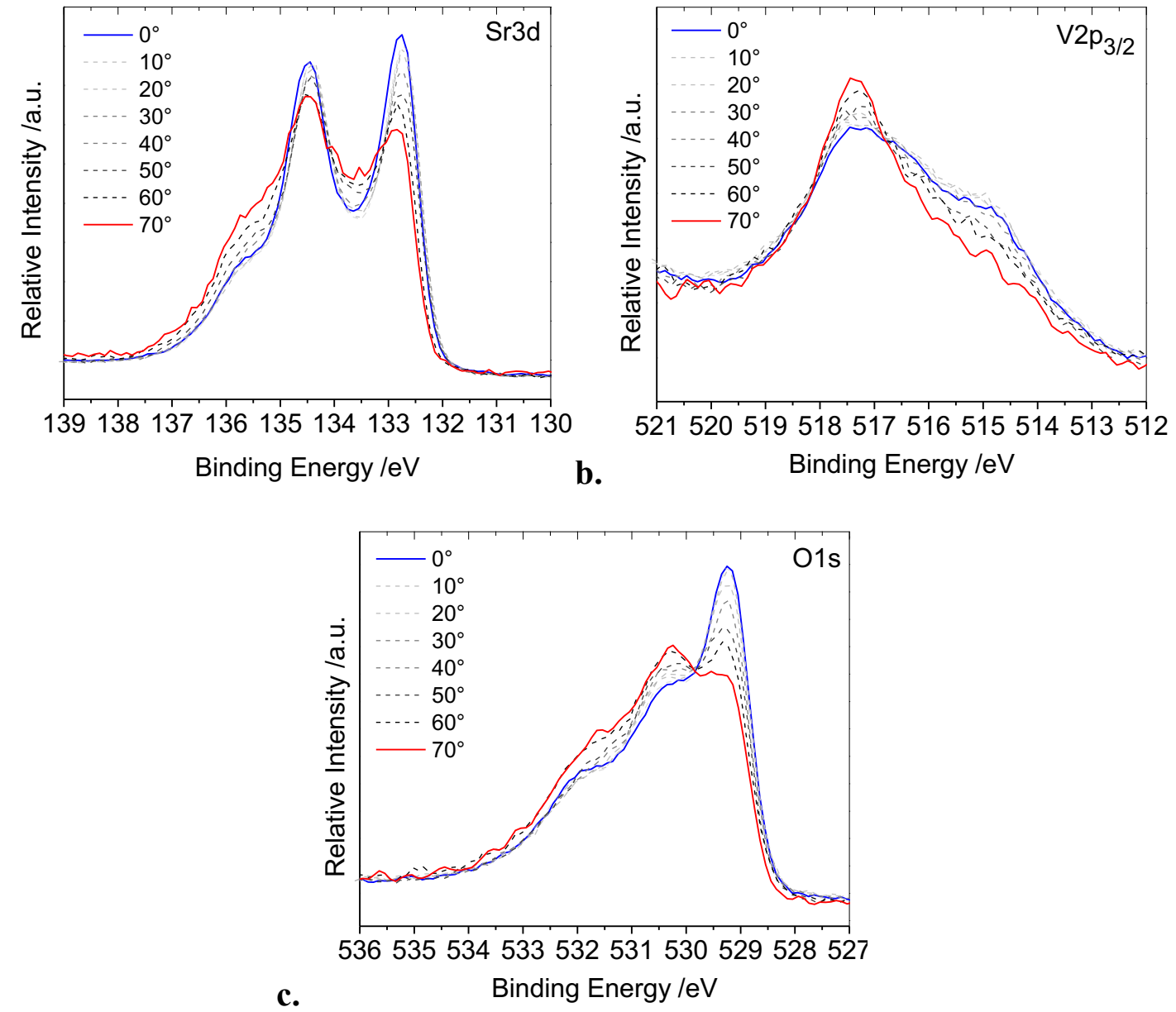

Figure 3: High energy resolution spectra of a. Sr3d, b. V2p $3 / 2$, and c. O1s regions of an as-grown $\mathrm{SVO}$ in angle resolved configuration, with a tilted angle $\theta$ from $0^{\circ}$ to $70^{\circ}$. 


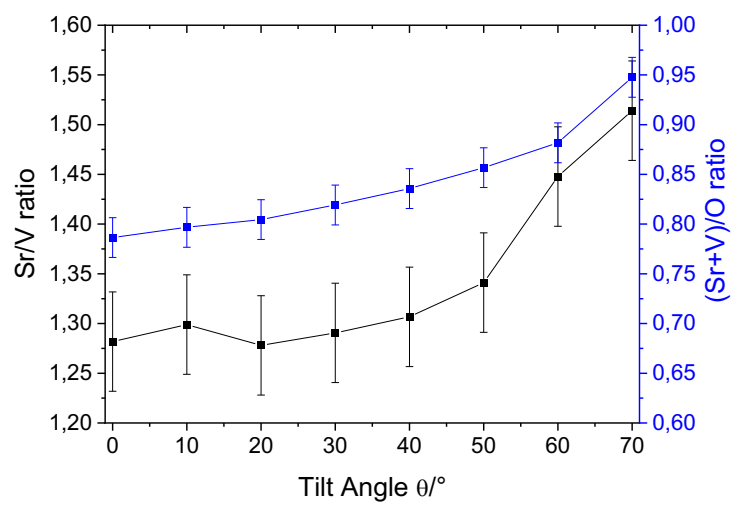

Figure 4: Evolutions of global $\mathrm{Sr} / \mathrm{V}$ and $(\mathrm{Sr}+\mathrm{V}) / \mathrm{O}_{\mathrm{ox}}$ ratios related to the tilt angle $\theta$ of an as-grown SVO (associated to AR-XPS spectra in figure 3) considering the total content of Sr3d and V2p $3 / 2$, and " $\mathrm{O}_{\text {ox }}$ " the total content of O1s exempt from the O1s (O-C, O-H) component related to organic surface contamination.

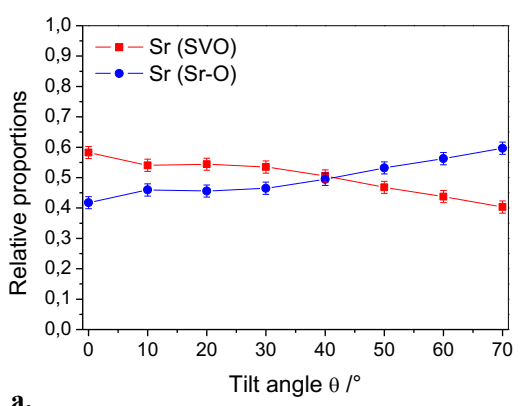

Figure 5: Relative proportions of the different chemical environments for a. Sr3d, b. $V 2 p_{3 / 2}$, and c. O1s spectral regions and their evolutions with tilt angle $\theta$, associated to angle resolved XPS spectra (figures 3) and peak attributions (figures 2) for an as-grown SVO. The standard deviation is settled to \pm 0.02 . 


\begin{tabular}{|c|c|c|}
\hline 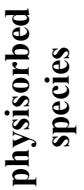 & $\begin{array}{c}\mathrm{O} 1 \mathrm{~s}(\mathrm{O}-\mathrm{C}, \mathrm{O}-\mathrm{H}) \\
\mathrm{C} 1 \mathrm{~s}\end{array}$ & 22.3 \\
\hline \multirow{3}{*}{ 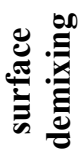 } & $\mathrm{Sr} 3 \mathrm{~d}(\mathrm{Sr}-\mathrm{O})$ & 6.5 \\
\hline & $\mathrm{V} 2 \mathrm{p}_{3 / 2}(5+)$ surface $\mathrm{V}_{2} \mathrm{O}_{5}$ & 2.7 \\
\hline & $\mathrm{O} 1 \mathrm{~s}(\mathrm{O}-\mathrm{M})$ from $\mathrm{SrO}$ and $\mathrm{V}_{2} \mathrm{O}_{5}$ & 9.0 \\
\hline \multirow{6}{*}{$\begin{array}{l}0 \\
0 \\
0 \\
0 \\
0 \\
\bar{\Xi} \\
\vdots\end{array}$} & Sr3d (SVO) & 9.0 \\
\hline & $\mathrm{V} 2 \mathrm{p}_{3 / 2}(5+)$ & 1.5 \\
\hline & $\mathrm{V} 2 \mathrm{p}_{3 / 2}(4+)$ & 4.0 \\
\hline & $\mathrm{V} 2 \mathrm{p}_{3 / 2}(3+)$ & 3.8 \\
\hline & O1s (lattice SVO) & 20.1 \\
\hline & O1s (surface SVO) & 5.8 \\
\hline
\end{tabular}

Table 2: Estimation of the chemical composition of an as-grown SVO at normal incidence $\left(\theta=0^{\circ}\right)$ with the different peak attributions. The standard deviation is settled to \pm 0.1 at. $\%$.

II/ As-grown SVO + H2O
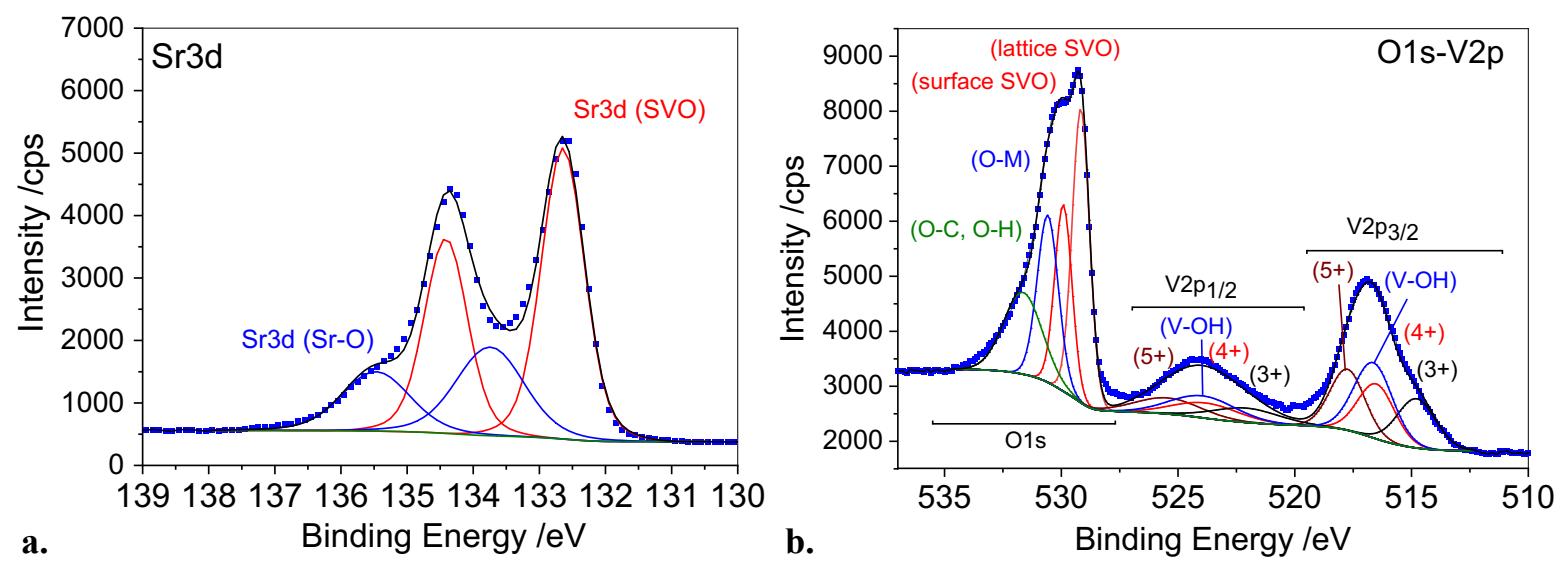

Figure 6: High energy resolution spectra of a. O1s-V2p and b. Sr3d regions with chemical environments attributed to the analysed as-grown SVO treated with $\mathrm{H}_{2} \mathrm{O}$ at normal incidence. 


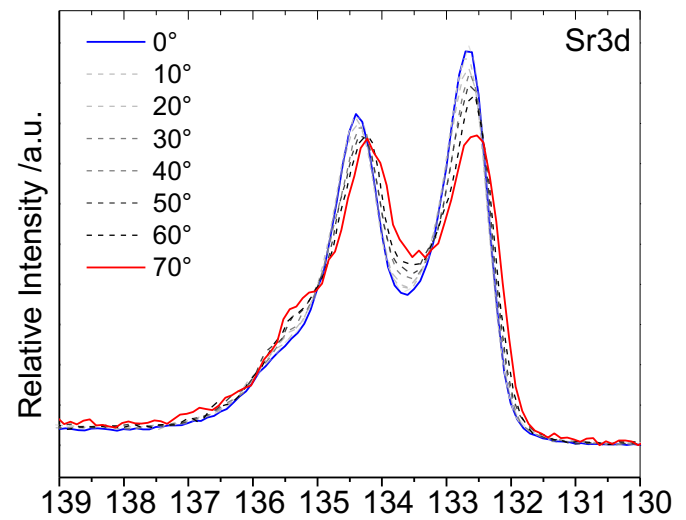

a.

Binding Energy /eV

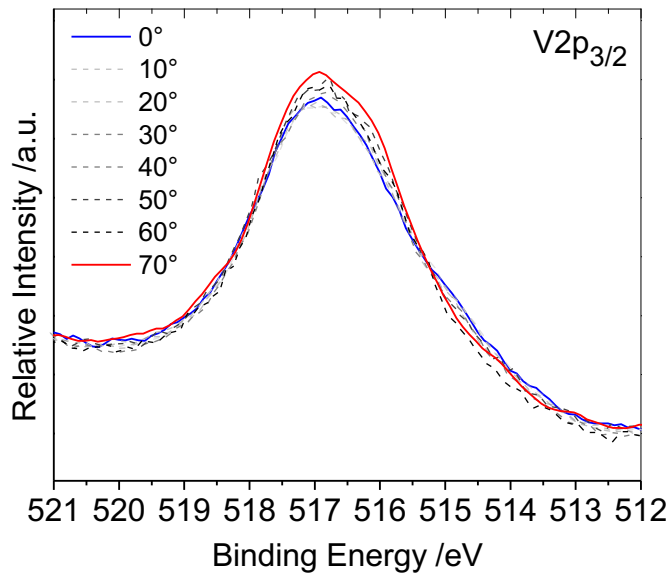

b.

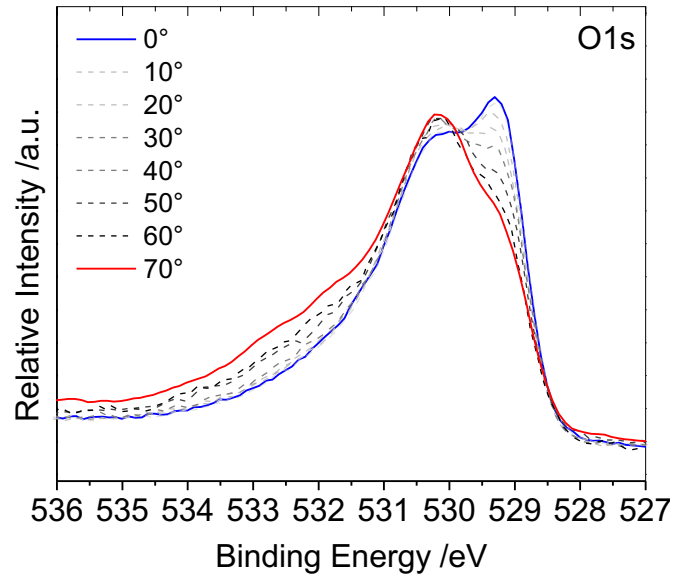

Figure 7: High energy resolution spectra of a. $\mathrm{Sr3d}, \mathrm{b}$. $\mathrm{V} 2 \mathrm{p}_{3 / 2}$, and c. $\mathrm{O} 1 \mathrm{~s}$ regions of an as-grown SVO treated with $\mathrm{H}_{2} \mathrm{O}$ in angle resolved configuration, with a tilted angle $\theta$ from $0^{\circ}$ to $70^{\circ}$.

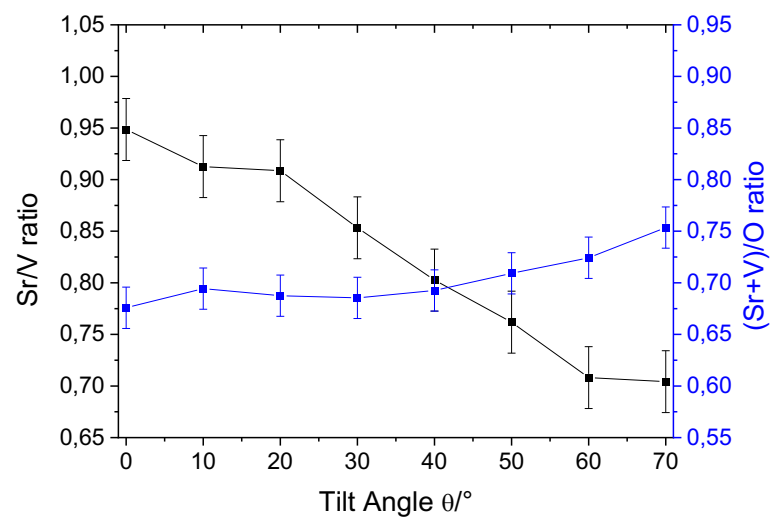

Figure 8: Evolutions of global $\mathrm{Sr} / \mathrm{V}$ and $(\mathrm{Sr}+\mathrm{V}) / \mathrm{Oox}$ ratios related to the tilt angle $\theta$ of an as-grown SVO treated with $\mathrm{H}_{2} \mathrm{O}$ (associated to AR-XPS spectra in figure 6) considering the total content of Sr3d and V2p $p_{3 / 2}$, and "Oox" the total content of O1s exempt from the $\mathrm{O} 1 \mathrm{~s}(\mathrm{O}-\mathrm{C}, \mathrm{O}-\mathrm{H})$ component related to organic surface contamination. 

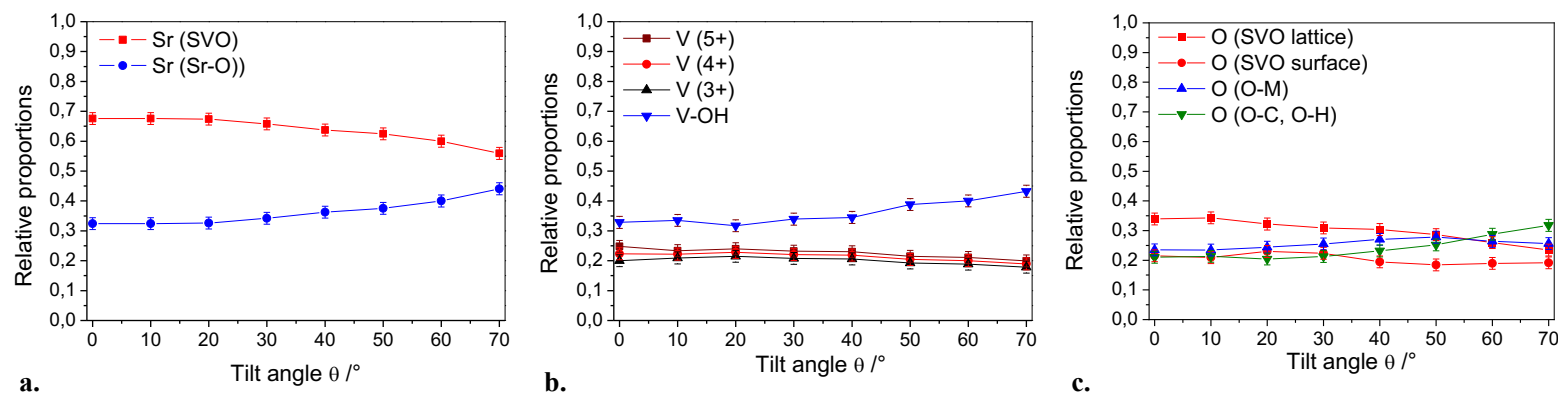

Figure 9: Relative proportions of the different chemical environments for a. Sr3d, b. $V 2 p_{3 / 2}$, and c. O1s spectral regions and their evolutions with tilt angle $\theta$, associated to angle resolved XPS spectra (figure 7) and peak attributions (figure 6) for an as-grown SVO treated with $\mathrm{H}_{2} \mathrm{O}$. The standard deviation is settled to \pm 0.02 .

\begin{tabular}{|c|c|c|}
\hline 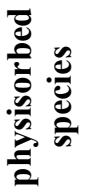 & $\begin{array}{c}\text { O1s }(\mathrm{O}-\mathrm{C}, \mathrm{O}-\mathrm{H}) \\
\mathrm{C} 1 \mathrm{~s}\end{array}$ & $\begin{array}{l}10.5 \\
23.2\end{array}$ \\
\hline \multirow{3}{*}{ 递 } & $\operatorname{Sr} 3 d(\mathrm{Sr}-\mathrm{O})$ & 4.2 \\
\hline & $\mathrm{V} 2 \mathrm{p}_{3 / 2}(-\mathrm{OH})$ & 4.5 \\
\hline & $\mathrm{O} 1 \mathrm{~s}(\mathrm{O}-\mathrm{M})$ from $\mathrm{Sr}-\mathrm{OH}$ and $\mathrm{V}-\mathrm{OH}$ & 11.8 \\
\hline \multirow{6}{*}{ 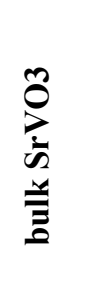 } & Sr3d (SVO) & 8.8 \\
\hline & $\mathrm{V} 2 \mathrm{p}_{3 / 2}(5+)$ & 3.4 \\
\hline & $\mathrm{V} 2 \mathrm{p}_{3 / 2}(4+)$ & 3.1 \\
\hline & $\mathrm{V} 2 \mathrm{p}_{3 / 2}(3+)$ & 2.7 \\
\hline & O1s (lattice SVO) & 17.0 \\
\hline & O1s (surface SVO) & 10.8 \\
\hline
\end{tabular}

Table 3: Estimation of the chemical composition of an as-grown $\mathrm{SVO}$ treated with $\mathrm{H}_{2} \mathrm{O}$ at normal incidence $\left(\theta=0^{\circ}\right)$ with the different peak attributions. The standard deviation is settled to \pm 0.1 at. $\%$. 

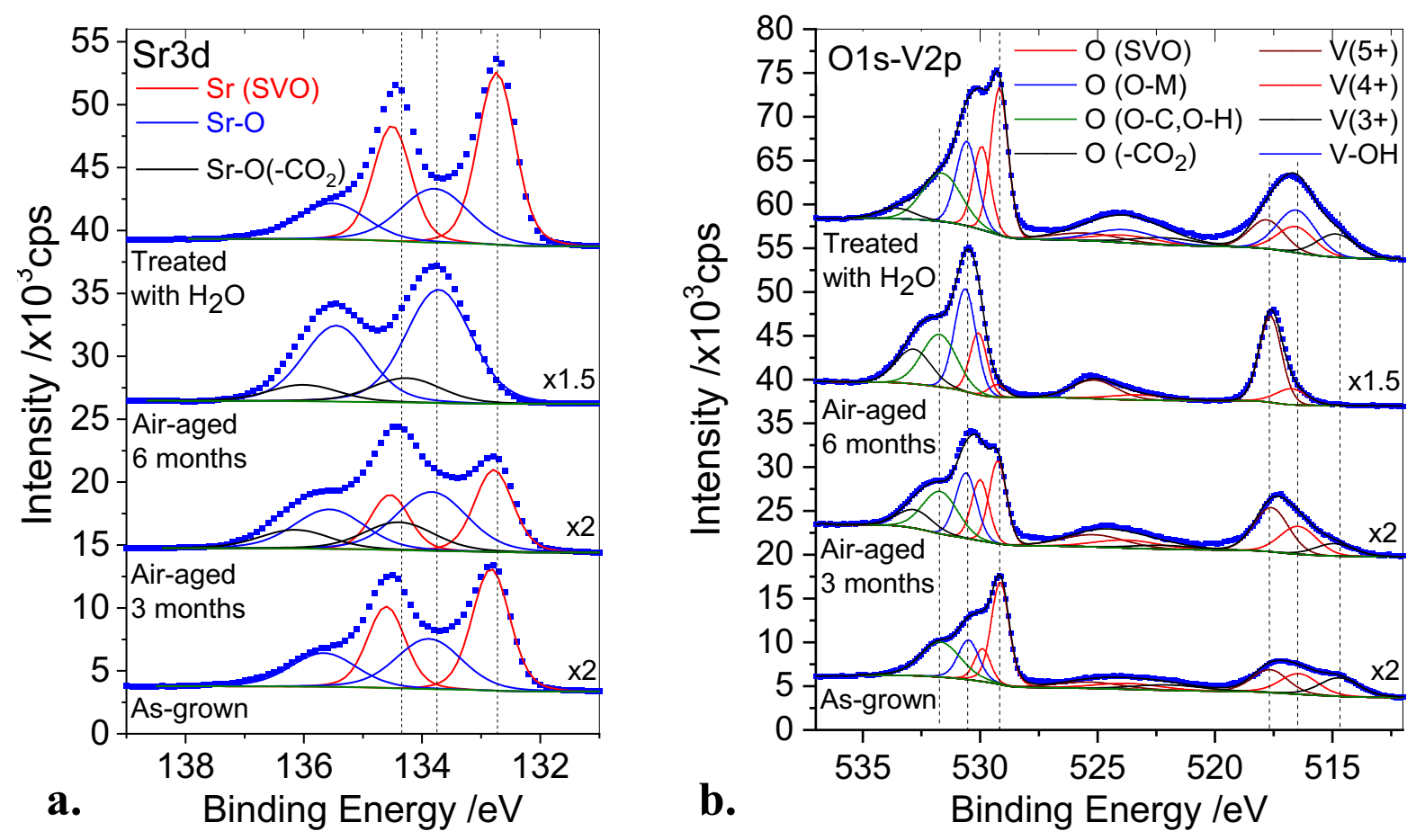

Figure 10: High energy resolution spectra of a. Sr3d, and b. O1s-V2p regions with chemical environments attributed to the following cases: (1) as-grown SVO. (2) after 3 months-ageing in air. (3) after 6 months-ageing in air. and (4) treated with water after ageing.

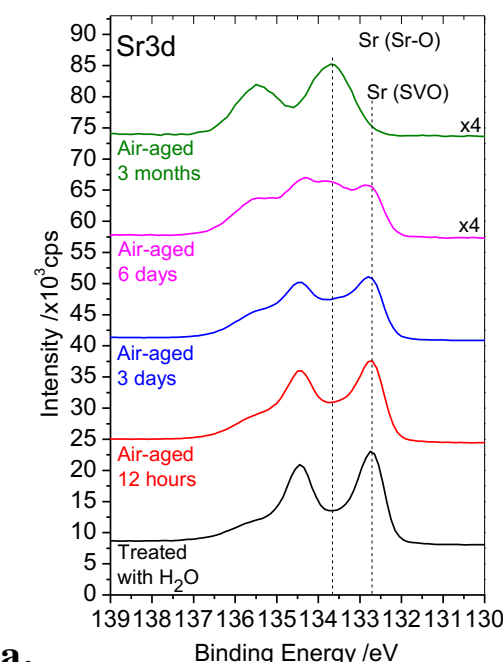

a.

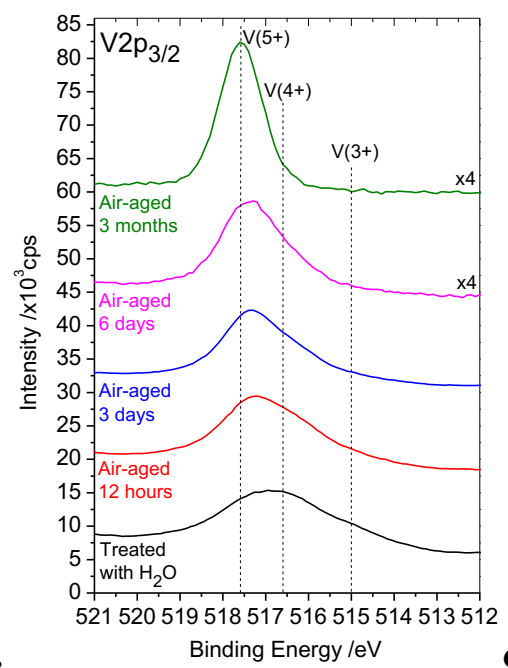

Figure 11: High energy resolution spectra of a. Sr3d. b. V2p $\mathrm{p}_{3 / 2}$ and c. O1s regions with chemical environments attributed to the following cases: treated with water. and successively air-aged for 12 hours. 3 days. 6 days and 3 months after rinsing. 


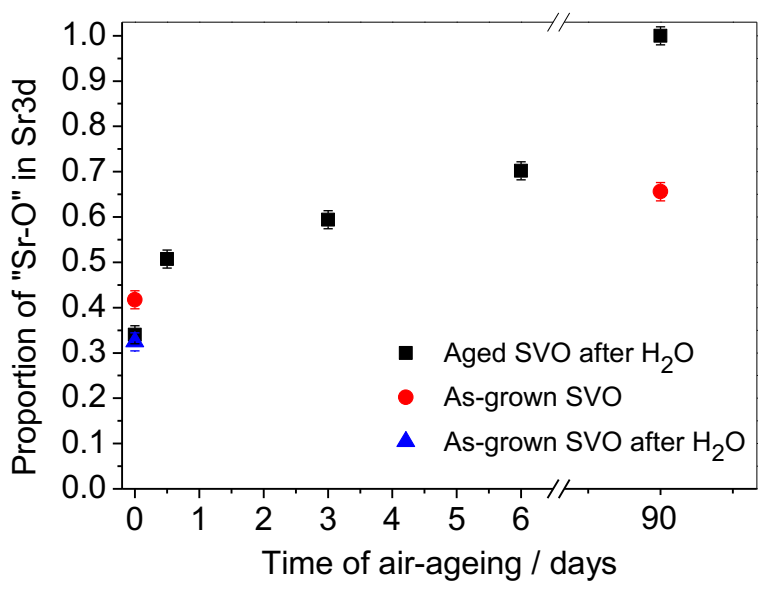

Figure 12: Evolution of the relative proportion of $\mathrm{Sr}-\mathrm{O}$ in $\mathrm{Sr3d}$ with the ageing-time of different SVO samples. 